This PDF is a selection from an out-of-print volume from the National Bureau of Economic Research

Volume Title: Deregulation and Interdependence in the Asia-Pacific Region, NBER-EASE Volume 8

Volume Author/Editor: Takatoshi Ito and Anne O. Krueger, editors

Volume Publisher: University of Chicago Press

Volume ISBN: 0-226-38674-0

Volume URL: http://www.nber.org/books/ito_00-1

Conference Date: June 19-21, 1997

Publication Date: January 2000

Chapter Title: Market Design and Price Behavior in Restructured Electricity Markets: An International Comparison

Chapter Author: Frank A. Wolak

Chapter URL: http://www.nber.org/chapters/c8478

Chapter pages in book: (p. 79 - 137) 


\title{
Market Design and Price Behavior in Restructured Electricity Markets An International Comparison
}

\author{
Frank A. Wolak
}

\subsection{Introduction}

Electricity supply is traditionally viewed as a natural monopoly. Economies of scale in the generation of electricity and the necessity of an extensive transmission and distribution network to deliver it to final customers seem to favor supply by a single firm for a given geographic region. However, Joskow (1987) argues that scale economies in electricity production at the generating unit level are exhausted at a unit size of about $500 \mathrm{MW}$. More recent econometric work finds that the null hypothesis of constant returns to scale in the supply of electricity (the combination of generation, transmission, and distribution) by U.S. investor-owned utilities cannot be rejected (Lee 1995).

There is also growing dissatisfaction with limited incentives for efficient operation faced by a cost-of-service-regulated or government-owned electric utility. According to this view, even if scale economies in the production of electricity exist, because of the incentives for input choice provided by the regulatory process or by state ownership the mode of production chosen by the firm does not allow them to be realized. For the case of a privately owned regulated utility, the firm earns higher returns for its share-

Frank A. Wolak is professor of economics at Stanford University and a research associate of the National Bureau of Economic Research.

The author thanks Marshall Yan for outstanding research assistance. Severin Borenstein, Jim Bushnell, and Richard Green provided very helpful comments on a previous draft. Partial financial support for this research was provided by the National Science Foundation. This paper reflects the state of electricity industry restructuring in England and Wales, Norway and Sweden, Australia and New Zealand as of 1 January 1998, unless otherwise noted. An up-to-date description of the status of electricity industry restructuring in these countries can be obtained from http://www.stanford.edu/ wolak. 
holders by choosing an input mix to satisfy the demand for its output that does not minimize total production costs. For the case of a governmentowned utility, the management chooses higher than cost-minimizing levels of labor or capital inputs to increase its political clout and long-term viability. Decision-making processes involving regulated utilities and regulatory bodies acting jointly or state-owned-enterprises have historically had difficulty making economically efficient new generation capacity investment choices in terms of both the size and the fuel type of the generating facility.

As consequence, regulators in the United States and worldwide have recently implemented new regulatory schemes and organizational forms in an effort to improve the incentives for efficient operation of electric utilities. Until very recently, in the United States this restructuring took the form of performance-based or incentive regulation plans, where the revenue a utility is allowed to earn is tied less to the cost of providing electricity and more to the attainment of performance goals as quantified by total factor productivity or some other measure of productive efficiency.

Other countries have undertaken more radical approaches to restructuring their electricity supply industries. Following the privatization of the majority of the generating assets of the formerly state-owned Central Electricity Generating Board, the privatization of all of the area boards (local electricity distributors), and the introduction of a market for generation in England and Wales (E\&W) on 1 April 1990, many Organization for Economic Cooperation and Development (OECD) member countries have formed wholesale markets for electricity and introduced varying degrees of competition into the retail side of the electricity supply industry. Most other OECD countries are currently in the process of implementing similar reforms.

The United States has been slow to undertake this radical restructuring process. As of 1 May 1999 only three regions of the United States operate competitive wholesale markets for electricity-California, PJM (all or part of Pennsylvania, New Jersey, Maryland, Delaware, Virginia, and the District of Columbia), and New England (Massachusetts, New Hampshire, Vermont, and Maine). The California market was the first to begin operation, on 31 March 1998. As of this same date, the incumbent investor-owned utilities in California faced competition for their retail customers. As of 1 May 1999, electricity industry restructuring activity exists through most of the United States. ${ }^{1}$ Retail competition of some form exists in all states with a competitive wholesale electricity market, as well as in many other states. Several other states in the United States have enacted

1. The Energy Information Agency of the U.S. Department of Energy maintains an upto-date web site on the status of electricity industry restructuring in each state. See http:// www.eia.doe.gov/cneaf/electricity/page/restructure.html. 
legislation to restructure their electricity industries. The vast majority of states have ongoing activity in the regulatory body that oversees the electricity industry (usually the public utilities commission) or in the state legislature dealing with electricity industry restructuring. Only two states have no significant ongoing activity in electricity industry restructuring.

All of the industry restructurings that have taken place in the United States and abroad are consistent with the view that competition should be introduced into the electricity supply industry wherever it is technologically feasible. Only those portions of the production process most efficiently supplied by a single firm should remain regulated. The prevailing view is that the technologies for electricity generation and retailing are both such that competition is feasible. As discussed above, economies of scale in generation are exhausted at levels of production significantly below current levels of industry output. Assuming that all retailers have equal access to the transmission and distribution network and electricity from the wholesale generation market, significant increasing returns to scale in electricity retailing are unlikely to exist. On the other hand, because competition in the transmission and distribution of electricity would require duplication of the current network, these two portions of the electricity supply industry are thought to possess the features of a natural monopoly. Therefore, the transmission and distribution sectors of the electricity supply industries in all of these countries are regulated to varying degrees.

Although privatization is often part of this restructuring process, for all of the regions described in this paper both state and privately owned companies compete in the electricity generation market. Some of the countries where restructuring has taken place only have municipally owned distribution companies, whereas others have only privately owned distribution companies. The remaining countries have distribution sectors composed of a combination of privately owned and government-owned companies.

The market structure and rules governing the operation of the electricity industries in these countries are not the direct result of independent actions by market participants-generators, retailers, and customers. Consequently, it is perhaps a misnomer to call these trading arrangements markets, because most markets or exchanges arise from the voluntary actions of buyers and sellers to form a self-regulating organization to facilitate mutually beneficial trades. Each of the electricity markets that currently exist around the world is the outcome of a deliberate government policy to restructure (and often privatize) the industry. The final form of the electricity industry in United States will be the result of joint decisions by state regulatory commissions and legislatures, as well as market participants. In addition, the Federal Energy Regulatory Commission must also approve all state restructuring plans. As I discuss later, the amount of 
regulatory oversight in the $\mathrm{E} \& W$ market has increased since the 1990 restructuring. The other newly established electricity markets are also subject to significant regulatory oversight. Even the New Zealand electricity supply industry, which touts its "light-handed" approach to regulation, has had a significant amount of government intervention since the market first began operation. All of the plans for establishing electricity markets in the United States mandate continual monitoring of the industry by both state and federal agencies. For all of these reasons, it is more appropriate to think of these restructured industries around the world and the proposed markets in the United States as alternative regulatory mechanisms to explicit price regulation for achieving the goals of greater economic efficiency in electricity supply.

From the perspective of economic efficiency, the optimal price for electricity should be set to mimic the market price in a competitive industry with many noncolluding firms and minimal barriers to entry. This price has several desirable properties. First, it gives firms the proper signals for the timing and magnitude of new investment expenditures. In addition, because firms have no influence over this market price, they have the maximum incentive to produce their output at minimum cost and can only earn higher profits by cost-reducing innovations not immediately imitated by competitors. The major impetus behind the liberalization of the $\mathrm{E} \& \mathrm{~W}$ market was the belief that this new form of market organization would come closer to achieving these regulatory goals for electricity prices than the preprivatization industry structure. ${ }^{2}$

This new form of "regulation" of the electricity supply industry gives rise to a new set of policy-making challenges associated with achieving economically efficient prices. The problem receiving the greatest attention is market power, which I define as the ability of a firm to cause a significant increase in the market price and to profit from this price increase. Firms subject to price regulation (either based on cost of service or an incentive regulation plan) have no direct control over the prices they can charge for electricity. Therefore, the explicit exercise of market power is not possible under traditional regulatory structures because the regulator, not the firm, sets the market price. A profit-maximizing regulated utility must use other means to increase its attractiveness to prospective shareholders.

In the markets for electricity currently operating around the world, firms explicitly bid prices at which they are willing to supply electricity. The desire of privately owned generation companies to maintain and attract shareholders implies that they will attempt to exploit any potential profit-making opportunities through their bidding behavior. For this rea-

2. An important concern expressed in a 1981 study by the U.K. Monopolies and Mergers Commission was that the preprivatization market structure did not provide the proper signals for constructing the optimal amount and type of new generation capacity in a timely manner (Armstrong, Cowan, and Vickers 1994, 291). 
son, from the perspective of consumer welfare, the success of a restructured electricity industry can be judged by the degree to which opportunities for significant economic profits are eliminated by the self-interested actions of producers and consumers governed by the current market rules and carried out within the existing market structure of the industry. ${ }^{3}$

There are many observable differences in market structure in the various restructured electricity supply industries. These differences in market structure have led to the imposition of market rules designed to mitigate the ability of firms to exercise market power in the form thought to be most prevalent given the market structure that exists in the industry. There are also many differences in market rules across these electricity industries that are due to historical reasons or engineering concerns about network integrity. The interaction of these market rules with the market structure of the industry determines whether economically efficient prices are set by these markets.

The purpose of this paper is to characterize this across-country relationship between market rules and market structure and spot prices for electricity using the restructured electricity markets in England and Wales, Sweden and Norway, the state of Victoria in Australia, and New Zealand. By studying the across-country relationship between market rules and market structure and the behavior of market-clearing prices, insights can be gained about how to set market rules to mitigate the incentives firms have to exercise market power for a given market structure.

The paper first describes the market structure and market rules governing the operation of each electricity supply industry. Because the E\&W electricity market was the first established among OECD member countries, it has served as a model for much electricity industry restructuring worldwide. Consequently, I first provide a detailed discussion of the market rules and market structure of this industry. Then I describe these two aspects of the joint Norway and Sweden electricity market (Nord Pool), the Victoria Electricity market (VicPool), and the New Zealand electricity market (NZEM) in light of the discussion of the E\&W market. Next I present various views of the time-series behavior of spot electricity prices in each of these markets and then relate these differences in the behavior of prices to observable differences in the market rules and market structure governing the operation of these electricity markets. This discussion focuses on linking differences in market rules and market structure to differences in the behavior of electricity prices across the countries.

Although a detailed analysis of how these across-country differences in market rules and market structure foster or mitigate the exercise of market

3. It is important to emphasize that firms can earn positive, zero, or negative accounting profits while earning zero economic profits. Zero economic profits implies that all factors of production are paid their opportunity cost. The opportunity cost of a piece of capital is the minimal return necessary to keep it from exiting the electricity supply industry. 
power is a topic for future research, I will also point out some very preliminary evidence consistent with the exercise of market power in the timeseries behavior of these spot prices. Where possible, I will attempt to link this price behavior that appears to be consistent with the exercise of market power to observable differences across the markets in the rules governing their operation and the structure of the industry.

\subsection{Industry Structure in the England and Wales Electricity Market}

The purpose of this section is to summarize the market structure and rules governing the operation of the E\&W system. I first describe the restructuring of the electricity industry in England and Wales. I then describe the major players in the market and their relative sizes and the mix of generation capacity they own. The discussion then focuses on the rules governing the operation of the E\&W electricity market. First I discuss the strategic weapons available to each of the market participants. Then I lay out the various stages of the price determination process and the potential opportunities for the exercise of market power that these rules create. I then discuss the evolution of the regulation of this market attempting to limit the market power of the two largest generators in the system.

\subsubsection{Market Structure in England and Wales}

Since 1 April 1990, all but a small fraction of electricity consumed in England and Wales must be sold through a mandatory day-ahead spot market for electricity with market-clearing prices set on a half-hourly basis. This market was formed as the end result of the breakup and privatization of the state-owned Central Electricity Generating Board (CEGB) and the privatization of the twelve area boards, the local electricity distribution companies, which were renamed regional electricity companies (RECs). The generating facilities of the CEGB were separated into three large companies. National Power and PowerGen took over all existing fossil fuel power stations. Nuclear power plants remained state owned, under the auspices of Nuclear Electric. ${ }^{4}$ The national transmission grid became the National Grid Company (NGC), which was jointly owned by the twelve RECs. In addition to the three large E\&W generators, Scottish nonnuclear companies (Hydro-Electric and Scottish Power), Electricity de France, and a number of independent power producers (IPPs) also sell electricity into the E\&W pool. The links to the E\&W market from Scotland and France are currently constrained by transmission capacity at $1.6 \mathrm{GW}$ and $2.0 \mathrm{GW}$. The maximum capacity available to serve the E\&W electricity

4. In July 1996, the U.K. government privatized the modern nuclear power stations, specifically the advanced gas-cooled reactors and the pressurized water reactor. British Energy became the holding company that owns these assets. 
market is approximately $60 \mathrm{GW}$, and the peak system demand is slightly more than $49 \mathrm{GW}$.

The restructuring process has transformed the electricity supply industry into four separate subindustries: (1) generation, (2) transmission, (3) distribution, and (4) retail sales. With some minor exceptions to be noted, the electricity supply industries in all subsequent restructurings have been subdivided in the same manner.

Because the technology of generation is thought to exhibit constant or decreasing returns to scale at current levels of production, a competitive market in generation is the foundation of all the restructured electricity industries I describe. Although the rules governing the operation of the market and the numbers, plant sizes, and mix of generating technologies employed differ greatly across the various industries, the goal of all of these markets is to foster economically efficient wholesale prices for electricity.

NGC runs both the financial and physical side the E\&W electricity market. It serves as both the power exchange and the independent system operator because it both determines half-hourly market-clearing spot prices for electricity and operates the national electricity transmission network, making generator dispatch decisions in real time to manage congestion on the grid and provide the ancillary services necessary to guarantee reliable power to all final customers. Originally, it was jointly owned by the RECs, but in 1995 it was separated and is currently traded on the London Stock Exchange.

Both transmission and distribution are thought to be natural monopolies, so that prices for bulk transmission provided by NGC are regulated by a price-cap mechanism. For the same reason, the distribution services provided by each of the RECs to customers in their service areas are regulated by a price-cap mechanism.

The retail side of the market is divided into franchise and nonfranchise customers. Nonfranchise customers are given the option of choosing their supplier from any of the twelve RECs as well as National Power or PowerGen directly. Initially, nonfranchise consumers were those with peak demands greater than 1 MW. On 1 April 1994, the 1 MW peak demand limit on these nonfranchise consumers was reduced to $100 \mathrm{~kW}$. This size restriction on customer peak demand ceases to exist on 30 June 1999, when all residential customers will be offered this option (i.e., all customers become nonfranchise). The RECs are required to allow competitors to transfer electricity over their distribution systems at the same price they charge to themselves to provide this service to their retail customers located in their own service areas.

Since the formation of the market, National Power and PowerGen have owned the majority of generating capacity and have produced at least 54.5 percent of total electricity sold during each of the fiscal years the pool has 
operated through 1995/96. PowerGen and National Power, most notably, have reduced their respective capacities steadily since the pool began. National Power began the 1990/9l fiscal year with approximately $30 \mathrm{GW}$ of capacity, and PowerGen had approximately $19 \mathrm{GW}$ of capacity. By the beginning of the 1995/96 fiscal year, these capacities were approximately 20 and $15 \mathrm{GW}$, respectively. Contrary to this trend by the two largest generators, several IPPs have entered the market, with, in most all cases, combined-cycle gas turbine technology generation facilities. The market share of electricity sold by these two dominant producers has declined, from 45.5 percent (National Power) and 28.4 percent (PowerGen) in the 1990/91 fiscal year to 31.38 percent and 23.12 percent for the $1995 / 96$ fiscal year. ${ }^{5}$ There has also been a significant amount of entry by independent electricity suppliers who purchase electricity from the pool and sell it to final residential and business customers via the distribution network of the REC serving that customer's geographic area.

Another important feature of the market structure is the similarity in fuel mix between National Power and PowerGen. As of 1 April 1995, National Power's capacity had the following approximate (because of fuelswitching capabilities) fuel mix percentages, 75 percent coal, 15 percent oil, 9 percent natural gas, and 1 percent hydroelectric. PowerGen's approximate mix was 70 percent coal, 16 percent oil, 13 percent gas, and 1 percent hydroelectric.

The vast majority of an RECs customers purchase electricity at rates fixed independent of within-year variations in the pool price. Before the start of the 1998/99 fiscal year, all residential customers paid fixed prices for electricity that could vary in a mutually agreed upon manner on a daily or weekly basis, independent of fluctuations in the pool price, for the entire fiscal year. The most common form of this pricing plan for residential customers had a fixed price per megawatt-hour for all consumption during the year, plus a fixed charge. Most of the remaining residential customers pay according to a fixed price per megawatt-hour for consumption during daylight hours and another fixed price per megawatt-hour for consumption during nighttime hours, plus a fixed charge. Almost all commercial and industrial users purchase power through similar annually negotiated fixed-price contracts, which also vary on a daily or weekly basis, independent of movements in the pool price. Consequently, within-day, day-today, or even month-to-month movements in the pool price have no impact on the prices all but a small fraction of customers pay because the pattern of prices they face does not change for the entire fiscal year. Only a very small fraction of E\&W total system load, approximately 5 percent, is pur-

5. Fiscal years run from 1 April to 31 March of the following calendar year. Nuclear Electric's 1995/96 fiscal year market share was 22.5 percent, power imported from Scotland and France was 8.71 percent, pumped storage was 0.7 percent, and IPPs and others was 13.6 percent (Electricity Association 1997, 26). 
chased by final consumers according to variations in the half-hourly spot market price. ${ }^{6}$

Because RECs provide electricity to the vast majority of their customers according to rate schedules fixed well in advance of the realization of pool prices, they normally hedge against this price volatility by purchasing "contracts for differences" (CFDs). CFDs are simply financial instruments guaranteeing prices at which an agreed upon quantity of electricity can be traded at a future date. ${ }^{7}$ CFDs have been sold by generators as well as financial institutions and traders that deal in commodity markets and derivative securities. It is important to emphasize that CFDs are not forward contracts to deliver electricity. The E\&W mandatory spot market structure does not allow physical bilateral trades between generators and their customers. Unless a generating facility is dispatched by NGC as part of the day-ahead spot-market-clearing process, that plant cannot produce electricity. Consequently, if a customer and generator sign a bilateral contract for electricity supply, this does not guarantee that the generator will be dispatched in a manner that matches the customer's half-hourly demands or any prespecified rate of production. Whether or not a plant is dispatched and the rate at which it is operated in a half-hour is the decision of NGC. A plant that is dispatched by NGC (that is, not constrained on) will receive the market-clearing spot price from the E\&W pool for all megawatt-hours it produces during that half-hour, regardless of the longterm contractual arrangements it has made with an REC or large customer in the CFD market.

CFDs were also used in the initial privatization process to maintain employment in the U.K. coal industry. The government required National Power and PowerGen to enter into contracts for the purchase of a higher volume of U.K. coal than they wished at higher-than-world-market prices, thus maintaining employment in the coal-mining industry. Vesting CFDs between each REC and National Power, PowerGen, and other generators were designed to compensate these generators for the higher prices they paid for U.K. coal under these coal supply contracts. The strike price of these CFDs allowed the costs of the coal contracts to be passed on to the RECs, and the structure of the REC regulatory process - a price cap with a Y-factor to pass through extraordinary cost increases-allowed these costs to be passed on to final customers in the form of higher retail prices.

6. Wolak and Patrick (1996b) describe these sorts of retail price contracts in more detail. Patrick and Wolak (1997) analyze the structure of demand under real-time prices for a sample of these customers from one of the RECs.

7. Most CFDs guarantee a fixed price for a fixed amount of electricity in the following manner. Suppose a generator and an REC write a CFD for $1 \mathrm{MWH}$ of power at a strike price of $£ 20 / \mathrm{MWH}$. If the spot price of electricity is greater than $£ 20 / \mathrm{MWH}$, then the generator pays the REC the difference between the spot price and $£ 20$ for the contracted $1 \mathrm{MWH}$. If the spot price is less than $\mathrm{f20} / \mathrm{MWH}$, the REC pays the generator the difference between

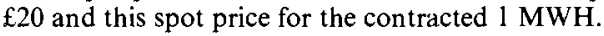


In the first two years following privatization, it is estimated that CFDs covered 84.3 and 89.1 percent, respectively, of National Power's and PowerGen's generation, declining to 72.7 and 70.6 percent over the next two years (Helm and Powell 1992). Green (1999) presents slightly larger estimates of the amount of contracts held by National Power and PowerGen over this time period using more up-to-date data.

\subsubsection{Market Rules in England and Wales}

For trading to take place in the E\&W market, participants must know how they are compensated for the bids that they submit, particularly how market-clearing prices are determined and how dispatch decisions for generators are made. Recall that generators offer or "bid" prices at which they will provide various quantities of electricity to the $\mathrm{E} \& \mathrm{~W}$ pool from their generating stations throughout the following day. They have two strategic weapons to influence the forty-eight half-hourly market-clearing electricity prices: (1) the daily decision for the price at which they are willing to supply electricity from a fixed portion of each generating facility and (2) the half-hourly decision whether to make that portion of each generating facility available to be called on by NGC to produce power. For example, in the $\mathrm{E} \& \mathrm{~W}$ market firms are allowed to submit three daily prices for a given generating unit, but the amount that they are willing to supply from that unit at each of these three prices can be varied on a half-hourly basis throughout the day.

The day-ahead bid prices and availability declarations submitted by generators are input into the general ordering and loading (GOAL) program at NGC to determine the merit order of dispatching generation and reserve capacity. The lowest price generating capacity is dispatched first, unless such dispatch will compromise system integrity. Subject to this caveat, dispatching plants in this "least cost merit order" gives rise to an upward-sloping aggregate electricity supply function for each half-hour of the following day. The system marginal price (SMP) for each halfhour of the following day is the price bid on the marginal electricity generating unit ("genset") required to satisfy NGC's forecast of each halfhour's total system demand for the next day, that is, the bid where this expected demand crosses the aggregate supply curve.

The methodology and data input into NGC's forecast of demand are readily available to generators prior to their submissions of bid prices and availability declarations for the next day (Baker 1992; Electricity Pool 1997; National Grid Company 1995). This implies that generators can compute NGC's forecast of demand for all forty-eight load periods during the next day before they submit their bid prices and availability declarations. Moreover, this demand forecast that sets the SMP is perfectly price inelastic. Wolak and Patrick (1996a) argue that these two market rules have important implications for the strategies used by generators to exercise market power. 
The pool purchase price (PPP), the price paid to generators per megawatt-hour in the relevant half-hour, is defined as

$$
\mathrm{PPP}=\mathrm{SMP}+\mathrm{CC} \text {, }
$$

where the capacity charge is CC $=$ LOLP $\times($ VOLL - SMP $)$, LOLP is the loss of load probability, and VOLL is the value of lost load. CC is intended to provide a signal to generators of the necessity of new generation capacity and to consumers that their consumption has a significant probability of requiring the maximum amount of generating capacity available in that load period. VOLL represents the per megawatt-hour willingness of customers to pay to avoid supply interruptions. It was set by the director general of the Office of Electricity Regulation (OFFER) at $£ 2,000$ /MWH for $1990 / 91$ and has increased annually in accordance with growth in the retail price index since that date. LOLP is determined for each half-hour as the probability of a supply interruption due to generation capacity being insufficient to meet demand. LOLP is a decreasing (at an increasing rate) function of the expected amount of excess capacity available during each half-hour period during the present day. ${ }^{8}$ The greater the amount of capacity available relative to expected demand in any halfhour, the lower LOLP and therefore the lower CC per megawatt-hour paid to generators. Wolak and Patrick (1996b) argue that this relationship has important implications for the two largest generators' strategies for obtaining high PPPs.

The pool selling price (PSP) is the price paid mostly by RECs purchasing electricity from the pool to sell to their final commercial, industrial, and residential customers. For the purposes of determining this price, the forty-eight load periods within the day are divided into two distinct price rule regimes referred to as Table A and Table B periods. During Table A half-hours the PSP is

$$
\mathrm{PSP}=\mathrm{SMP}+\mathrm{CC}+\mathrm{UPLIFT}=\mathrm{PPP}+\mathrm{UPLIFT},
$$

where UPLIFT is a charge used to collect costs incurred when demand and supply are actually realized each day. UPLIFT is only known after the following day's electricity demand has actually been satisfied. It is the only price uncertainty from the day-ahead perspective, and it is collected over at least twenty-eight Table A pricing periods each day. UPLIFT is zero for Table B pricing periods. Recall that the E\&W market is an ex ante market in the sense that the PPP is set on a day-ahead basis using a demand forecast rather than actual demand. The costs of supplying the difference between the forecasted demand and the realized demand for the day is therefore recovered through the UPLIFT charge.

This charge also compensates generators for reserve plant available but

8. LOLP also depends on capacity offered in that half-hour during the seven previous days. Wolak and Patrick (1996b) describe the structure of the LOLP function in detail. 
not actually used to meet demand and start-up costs. Generators are paid for being available to produce electricity according to

Availability payment $/ \mathrm{MWH}=\mathrm{LOLP} \times(\mathrm{VOLL}-\max [\mathrm{SMP}$, Bid price] $)$.

This approach to setting availability payments compensates a relatively high priced plant that is not used but is available less than a plant that bids close to the SMP. The remaining portion of UPLIFT consists of NGC's costs of ancillary services (reactive power, frequency control, hot standby, and black-start capability).

By 4 P.M. each day, the SMP, CC, and the identities of the Table A and Table B periods for all forty-eight load periods for the following day are communicated to pool participants. UPLIFT averages less than 10 percent of the PSP, and as discussed in Patrick and Wolak (1997), it can be accurately forecast on a day-ahead basis. Consequently, a large fraction of the ex post PSP is known on a day-ahead basis.

\subsubsection{Regulatory Oversight in England and Wales}

The Electricity Act of 1989 established OFFER, with Professor Stephen Littlechild serving as director general, to oversee the operation of the restructured U.K. electricity industry, from generation to transmission and distribution to final customers. At privatization there were no explicit controls over the PPP. Since then, Littlechild has instituted several regulatory changes in an attempt to inhibit strategic price and supply schedule offerings by generators. These include (1) an amendment of the original generation license to require generators to make public their plans on capacity availability, (2) a change in the way LOLP is calculated, (3) voluntary price caps on the time-weighted and quantity-weighted values of PPP, (4) the divestiture of generating plant, and (5) incentive mechanisms to reduce the magnitude of UPLIFT payments.

The original generation license was revised, following the Pool Price Inquiry in December 1991, to restrict the ability of generators to manipulate the PPP by reducing the capacity made available to the pool. The changes require generators to provide, for public viewing, reports containing their criteria for determining the availability of their capacity to the pool, closing generating stations, and otherwise reducing generating capacity. Each year, generators must also file detailed forecasts of the availability of each generating unit for the coming year and, at year's end, file a "reconciliation" explaining any deviations from anticipated availability. This information is also publicly available. However, "generators are under no obligation under Pool Rules to declare any of their Centrally Dispatched Generating Units (CDGUs) available to generate at any particular time, even though the CDGU may be operationally available" (Electricity Pool, n.d., 10). Wolak and Patrick (1996b) describe various other actions by the director general to encourage generators to declare capacity available. 
During late 1993 and early 1994, OFFER issued reports and statements claiming that National Power and PowerGen were exercising market power to drive up pool prices. This matter was resolved with the institution of caps on time-weighted and quantity-weighted pool prices over the fiscal years 1994/95 and 1995/96 as part of a voluntary agreement, reached 11 February 1994, between National Power, PowerGen, and OFFER after Littlechild threatened to refer these generators to the Monopolies and Mergers Commission. ${ }^{9}$ This agreement also included the divestiture of 4 and $2 \mathrm{GW}$ of coal or oil generating plant by National Power and PowerGen, respectively.

As a result of UPLIFT increases in the 1993/94 fiscal year, OFFER instituted in April 1994 the "uplift management incentive scheme" (UMIS) in an attempt to encourage NGC to minimize "avoidable costs" incurred in operating the E\&W electricity market. UMIS was then replaced with the "transmission services scheme" (TSS) on 1 October 1995. TSS divided UPLIFT into the costs associated with reactive power, system constraints, transmission losses, and other ancillary services. Each category has a target level of costs, and NGC was given a share of any savings below these targets as an incentive to keep these costs down. Total ancillary services costs in all subsequent fiscal years are significantly below their 1993/94 level despite continuing growth in total annual energy production in the E\&W system.

\subsection{The Electricity Supply Industry in Norway and Sweden}

Beginning 1 January 1996, the world's only international power exchange opened in Oslo, Norway. Statnett Marked AS, a subsidiary of the Norwegian grid company, Statnett SF, has been operating the Norwegian power market since 1993. From 1991 to 1993, Statnett SF managed both the national grid and the power market, which was introduced following the Norwegian Energy Act of 1990. With the formation of the international Nordic power market, Statnett Marked AS changed its name to Nord Pool ASA; it is currently owned $50 / 50$ by Statnett SF and Svenska Kraftnät, the Swedish national grid operator. This power exchange integrates the Norwegian and Swedish electricity systems with ninety-six Norwegian and twenty-one Swedish participants as of March 1996. Denmark, Finland, and Russia all have participants in the market. Statnett SF is owned by the Norwegian government and Svenska Kraftnät by the Swedish government.

9. The Electricity Act of 1989 gives the director general the authority to refer firms to the Monopolies and Mergers Commission in order to make changes in the relevant license. Referrals can also be made under the Fair Trading Act of 1973 or the Competition Act of 1980 . 


\subsubsection{Market Structure in Norway and Sweden}

There are three major differences between the Nord Pool market structure and the E\&W market structure. First is that 99 percent of installed capacity in Norway is hydropower, with the remaining capacity primarily oil and gas thermal power. In Sweden, approximately half of the total installed capacity is hydropower. Nuclear power has the next highest capacity share, approximately 30 percent. Except for a small amount of renewable generation capacity, oil and gas make up the remaining thermal power capacity. Consequently, more than 85 percent of the generation capacity in Norway and Sweden is either hydropower or nuclear power, technologies that have very low marginal costs of producing electricity. In contrast, more than 80 percent of the generating capacity in the United Kingdom is higher marginal cost coal-, oil-, or gas-fired generating technology.

The second major difference is that Nord Pool is not a mandatory pool. Generators and consumers decide whether they wish to sell or purchase electricity through this market. As a consequence, the majority of electricity in Norway and Sweden is still traded via bilateral contracts between generators and consumers, with the pool serving primarily as a wholesale market for marginal energy supplies. Nord Pool is actually composed of two markets operating simultaneously with the bilateral contract market. During any hour in the day electricity is transacted on each of these markets and through bilateral contracts. In addition, there is a futures market where weekly financial futures contracts with maturities ranging from a week ahead to three years ahead are traded. The market most like the $\mathrm{E} \& W$ market is the daily power market (DPM), or Elspot market. Here fixed quantities of electricity are traded at prices set on a day-ahead basis for twenty-four hourly periods. Because of differences between day-ahead electricity consumption and generation plans and actual consumption and generation plans, incremental electricity must be dispatched throughout the day to meet unexpected demand and to maintain system integrity. This market for within-day electricity is called the regulation power market (RPM) in Norway and the balancing market in Sweden.

The final difference between Nord Pool and the E\&W industry is that much of the generation capacity is fully or partially state owned. When the Energy Act of 1990 "deregulated" the electricity supply industry in Norway, Statkraft, the state-owned integrated electricity supplier, was broken up into separate companies providing generation, transmission, and distribution services similar to the CEGB in England and Wales, but it was not privatized. Statnett SF was created as the state-owned national grid company and system operator. Statkraft SF retained all generating plants. Statnett Marked AS was subsequently formed to run the electricity market. Statkraft SF owns approximately 40 percent of Norway's hydro- 
electric capacity and produces approximately 30 percent of its electricity output. The second largest producer in Norway is Hydro Energy, a subsidiary of Norsk Hydro, the largest industrial end user of electricity in Norway. It produces approximately 10 percent of Norway's electricity output. Many other smaller firms generate the remaining 60 percent of Norwegian electricity production. The vast majority of this capacity is owned by municipalities. Different from Norway, where there are more than two hundred generation companies (many of whom do not trade in the spot market), in Sweden ten large generators produce more than 90 percent of Swedish electricity. Vattenfall, the Swedish state power board, generates approximately 50 percent of the electricity produced in Sweden. In both countries, the majority of distribution assets are municipally owned. In Sweden, some of the large retail distributors also generate all or a large fraction of the electricity they distribute. For example, Sydkraft and Stockholm Energi, the two largest distribution companies, are the next largest generators after Vattenfall. In Norway, about half of the two hundred distribution companies also own generation assets.

\subsubsection{Market Rules for Nord Pool}

The rules governing the operation of the Nord Pool DPM differ from those for the E\&W market in a number of dimensions. First, as discussed above, the DPM only trades a small fraction of the electricity produced within any hour during the day. In 1994, 14.6 TWH of electricity was sold on the spot market ( $1 \mathrm{TWH}=10^{9} \mathrm{kWH}$ ). In 1995, this figure rose to 20.0 TWH. Total Norwegian electricity production was 113.6 TWH in 1994 and 123.5 TWH in 1995, which implies only 12.8 and 16.2 percent, respectively, of total Norwegian generation was sold through the DPM in these two years. In 1996, 40.6 TWH was sold in the new international DPM. Comparing this figure to $240.9 \mathrm{TWH}$, the total amount of generation in Norway and Sweden in 1996, implies that 16.7 percent of the production of the two countries is sold through this market. Sales in the RPM have remained stable over the three complete years Statnett Marked has operated: 5.5 TWH of sales in 1993, 6.1 TWH in 1994, 5.6 TWH in 1995, and 5.9 TWH in 1996. This is because the primary function of the RPM is to resolve imbalances between planned consumption as of the beginning of the hour and actual consumption during the hour. These consumption plans can be hedged on through bilateral contracts or on the DPM. Prices in the RPM very closely track those in the DPM, although they appear slightly more volatile. With the formation of the international DPM on 1 January 1996, the Swedish national grid company and system operator, Svenska Kraftnät, formed a similar within-day power market, which it calls the "balancing market" (Balansetjänesten).

The Eltermin market originally sold forward contracts for physical delivery in the future. Beginning in 1995, this market was transformed into 
a financial market that sells what are called Eltermin contracts, which are obligations to buy or sell a known quantity of electricity in a specific period of time at a price agreed upon at the time the contract is entered into. The contracts do not lead to physical delivery when they become due. Financial settlement is done against the DPM spot price.

Eltermin contracts are either forward or futures contracts. The forward contracts are traded for blocks of power either for thirds of the year or for the entire year. These forward contracts are CFDs on blocks of power for the contract period. When the contract becomes due it is settled against the price in the Elspot market.

Eltermin futures contracts are standardized along various dimensions. There are three different time horizons to these contracts: (1) week-long contracts, ranging from up to four to seven weeks in the future; (2) block contracts of four weeks long, for electricity delivered up to a year in the future; and (3) seasonal contracts for blocks lasting an entire season of the year, for electricity delivered over one year in advance. The final dimension of the contracts is the time period within the day that the contract is valid. There are three types of contracts along this dimension: (1) basic power, all hours in the week (168 hours); (2) day power, from 7 A.M. to 10 P.M. Monday to Friday (75 hours); and (3) night power, the remaining hours not covered by the day power contract. There is continuous trading in this market five days each week, with sellers submitting ask prices for the contracts they wish to sell, buyers submitting bid prices for the contracts they wish to purchase, and trades taking place when bid prices exceed ask prices. These contracts are purely financial contracts in the sense that financial settlement takes place daily for customers holding futures contracts, based on the day-to-day changes in the relevant Eltermin prices. During the delivery period, financial settlement of the contract takes place at the difference between the last price in the Eltermin market and that hour's price in the DPM. Volume in this market has grown significantly over time. In 1994, total trading volume over all contracts was 7.1 TWH. In 1995, this figure more than doubled to 15.5 TWH. In 1996, the figure tripled to 42.6 TWH. The greatest growth has been in the weekly and block contracts, with only moderate growth in the seasonal contracts.

The DPM is similar to the E\&W market in the sense that generators submit their bids to Nord Pool on a day-ahead basis. However, because this market operates on top of the bilateral contract market, it is what Nord Pool calls a "netto-market" in the sense that each customer must be in balance during each hour the following day-its supply obligations must equal the sum of its own generation, bilateral contract purchases from other generators, and DPM purchases. The bid function submitted by a DPM market participant gives the amount of power it will actually sell or buy each hour as a function of the market-clearing price. Recall that by law all but a very small fraction of total generation in the E\&W 
market must be sold on the spot market during each half hour. In addition, the aggregate demand determining the market-clearing price in the $\mathrm{E} \& \mathrm{~W}$ market is the value forecast by NGC, whereas in the DPM, the marketclearing price for each half-hour is determined at the intersection of the aggregate demand and supply bid functions. For this reason, the DPM can also be thought of as a forward market for firm delivery during the following day. Different from the E\&W market, there is no uncertainty in the quantity of electricity that is traded on the spot market the next day. In the E\&W market, the difference between day-ahead generation plans and actual generation is handled through the UPLIFT charge. Generators in the E\&W market submit their willingness to supply a specific quantity of electricity during the following day. This means that they are at risk to sell more or less than their willingness to supply at the PPP, depending on actual market conditions. In Nord Pool, because of the presence of the RPM, the DPM is a firm financial commitment for a fixed price and quantity of electricity sold on a day-ahead basis. For this reason, one can also think of the DPM as a day-ahead market for CFDs written against the RPM price.

There is also a geographic dimension to the price-setting process in the DPM that is different from the $\mathrm{E} \& \mathrm{~W}$ market, where there is a single price for electricity in each half-hour, except for electricity produced by constrained-on generators. Every Wednesday, Nord Pool sends to market participants either electronically or by fax two types of information about how bids should be submitted for trade in the DPM during the following week. This information defines the geographic areas of Norway and Sweden for which participants will submit bids. These bid areas are determined using historical generation and consumption data, transmission capacity, and the description of the electricity grid. If a transmission bottleneck is expected to occur between two geographic areas during the week, separate bid areas will be defined on either side of the transmission bottleneck. These bid areas can also change over the course of the week based on planned or unplanned bottlenecks in the transmission grid. The second type of information Nord Pool supplies to participants is the bid price interval, giving the highest and lowest prices that must be covered by a bid from each participant for all hours in the coming week. This is done to guarantee a unique price for each bid area. The bidder can submit a maximum of fourteen prices between these two prices, giving the amount it is willing to buy or sell as a function of these prices.

All bids by market participants must be registered in standardized bid forms, one for each bid area, and submitted electronically or by fax to Nord Pool by noon the day before actual physical delivery takes place. The bid gives the maximum hours the bid is valid (minimum one hour and maximum all of the hours a bid area is valid). These bids must be finalized by noon the day before power will be delivered on the DPM. By 2 P.M. 
that same day, Nord Pool takes this information and determines the market-clearing prices for each of the twenty-four periods starting with midnight to 1 A.M. the following day and ending with the period starting at 11 P.M. and ending at midnight the day after. The system price is determined from the intersection of the aggregate electricity supply function (bids to supply electricity as a function of price) with the aggregate electricity demand function (bids to consume electricity as a function of price) without taking into account transmission constraints. If there are no transmission constraints, then all generators receive the same price for the electricity they produce.

If there are transmission constraints, generators in different bid areas receive different prices for the electricity they produce in the form of different transmission capacity fees across the different bid areas. Similarly, consumers in these bid areas purchase at different prices because of these capacity fees. In areas where generators want to sell more than can be transmitted, they will be required to pay a capacity fee to do so. Consumers in these bid areas will receive this capacity fee for all of their consumption in this area. In areas where bidders want to purchase more than generators are willing to supply, the price will be increased by a potentially different capacity fee. Generators in this area will receive this capacity fee in addition to the spot price for their generation. Prices in the surplus generation area will fall and prices in the deficit generation area will rise until the amount electricity generators in the surplus area are willing to transmit to the deficit region equals the amount consumers in the deficit region are willing to take, and both are equal to the transmission capacity between the two bid regions. These actions by Nord Pool end when all transmission bottlenecks are eliminated. ${ }^{10}$ Bid areas that set the same prices are aggregated into common price areas. Market participants are then notified of these price areas, area prices, and the hours they are valid. Each participant is told the contractual amount of electricity it will be called on to buy or sell in each price area during each of these hours and the total amount of power transacted on the DPM during each hour. If there are no transmission bottlenecks, the entire system becomes a single price area.

The forward contract nature of the DPM is another way that it differs from the E\&W spot market. In the E\&W market, generators only know the market-clearing price for the next day; they do not know exactly how much electricity they will be required to supply to the spot market during each half-hour that day until the half-hour actually occurs. However, the presence of RPMs in Norway and Sweden, which operate during the next

10. Because of very extensive transmission networks in Norway and Sweden, transmission bottlenecks rarely occur within the two countries. The major source of bottlenecks is trading between the two countries. 
day to balance any discrepancies in a generator's or consumer's contractual supply or demand obligations (including those from the DPM), fulfills this role in the Nordic power market. These unexpected deviations from plans are made up by purchases or sales into this market, so that the DPM clears the day before actual dispatch takes place. Consequently, the DPM is simply another contractual supply or consumption obligation (similar to a bilateral contract) market during the day actual supply or consumption takes place. In the E\&W market, NGC serves the function of the RPM because it dispatches generation during the following day to supply the amount of electricity actually demanded (rather than the expected demand used to set the PSP) and to maintain system balance.

During each dispatch day for the DPM, an RPM operates in each country. The equation Production + Import $=$ Consumption + Grid losses + Export must hold for each bid area. In Norway, each day before 7:30 P.M., bids are registered with the RPM. Generating stations that bid have to be able to alter their production within fifteen minutes. A bid is an option for the system operator and can take two forms. An upward regulatory bid indicates the price the market participant demands for an extra amount of power produced. A downward regulatory bid sets the price that actor is willing to pay for buying power (by producing less than planned). All bids are grouped according to price areas and sorted by price. The RPM in each bid area uses these bids to increase or decrease production in these areas. The market participant called on to increase or decrease its output is given at least fifteen minutes' notice before it must produce. It is given no indication of how long it must produce but will be given at least fifteen minutes' notice before it must shut down. When an hour of regulation has passed, the price in the RPM is fixed and one price is set for each price area. After each hour, each participant in the DPM calculates its imbalances in each price area - how much more or less than it contracted for on the DPM did it actually consume or produce in that hour? This imbalance is settled in the RPM. If a participant consumes more than planned, it must buy in the RPM, and if it consumes less than planned, it must sell in the RPM. This implies that all DPM and bilateral market participants, even if they do not submit bids to the RPM, are involved in this market.

The regulation market in Sweden operates in a different manner. By law, Svenska Kraftnät has the obligation to maintain balance between generation and load in Sweden. All consumers of electricity are required to ensure that a "balance provider" has been appointed for their point of withdrawal from the grid. Since 1 January 1995, Svenska Kraftnät has operated the "balance service," which involves agreements with approximately forty balance-responsible companies called "balance centers." These companies have the responsibility in accordance with the Balance Obligation Agreement to provide the Swedish electricity system with the same amount of electricity that the balance center's customers are consuming. 
Svenska Kraftnät is responsible for the balance settlement, that is, the calculation of the imbalance, of every balance center. It then operates an hourly market for imbalances that allows trading of electricity across balance centers. Because of this congestion management scheme, Sweden is always a single bidding area in the Nord Pool bidding process.

\subsubsection{Regulatory Oversight of the Nordic Power Market}

Up until the formation of the international power exchange between Sweden and Norway, the Norwegian Water Resources and Energy Administration (NVE) oversaw the operations of the Nordic power market. It is still responsible for monitoring grid operations in Norway and is responsible for setting the tariffs for the local distribution companies throughout Norway. Previously, distribution tariffs were set on a cost-of-service basis, but starting in 1997, NVE implemented a version of price-cap regulation. Because Nord Pool is not required by the Swedish government to operate under any particular license, the majority of formal monitoring of Nord Pool remains with NVE.

There have been several inquiries into the reasons for high prices in Nord Pool. Following the formation of the Norwegian power market in 1991, prices were the lowest they had ever been. These prices continued until Statkraft SF publicly announced a policy of not supplying to the spot market at prices below $100 \mathrm{NOK} / \mathrm{MWH}$. Statkraft apparently demonstrated its determination to maintain market-clearing prices above this level by punishing deviators by flooding the market and driving prices to zero. Prices subsequently stabilized at significantly higher values. Annual mean prices in the spot market have been above $100 \mathrm{NOK} / \mathrm{MWH}$ for all years following 1992. The Norwegian Competition Authority (Prisdirektoratet) investigated whether collusion between generators caused these elevated prices, but it found little evidence in favor of this claim. Other periods of extremely high prices seem to be explained by unusually dry weather conditions.

\subsection{The Victoria Electricity Supply Industry}

The state of Victoria has the longest running wholesale electricity market in Australia. The Victoria Power Exchange (VPX) was established under the Electricity Industry (Amendment) Act of 1994 and formally began operation on 1 July 1994. New South Wales (NSW) established a statelevel wholesale market for electricity that began operation 10 May 1996. Effective 4 May 1997 interstate electricity competition between generators in NSW and Victoria to supply electricity to energy retailers in these two states began. Previously, trade between NSW and Victoria was limited to long-term contract transactions, and any short-term trades were based on system integrity considerations rather than economic considerations. The 
integration of these two markets to allow all feasible trades between the two states is the first stage in the establishment of the National Electricity Market for Australia, known as NEM1.

The ultimate goal of this process is to establish a single electricity market across Queensland, NSW, Victoria, and South Australia. Because the eastern seaboard of Australia is currently not a fully integrated system, modifications of the system must be completed before a competitive interstate market can be introduced. Following a process similar to the one that occurred in England and Wales, the plan is to separate transmission and distribution from generation for all of the vertically integrated and formerly government-owned utilities throughout Australia and privatize or corporatize these new entities. One outcome of this process is a harmonization of the rules governing the operation of the two markets currently in operation in Victoria and NSW. The market structures of the two electricity supply industries in Victoria and NSW are also similar in terms of the relative sizes of the generation firms and the mix of generation capacity by fuel type, although the NSW industry is a little less than twice the size (as measured by installed capacity) of the Victoria industry and the largest three generators in NSW control a larger fraction of the total generation capacity in their market than the three largest generators in Victoria control of their market. Because the NSW market has operated for a short time and shares many market rules with the Victoria market, my discussion will focus on the Victoria industry. ${ }^{11}$

\subsection{Market Structure in the Victoria Electricity Supply Industry}

Restructuring and privatization of the State Electricity Commission of Victoria (SECV) in 1994 took place at roughly the power station level. The generation sector was formed into five separate entities to be sold. As of 28 March 1999 when Ecogen Energy was privatized, all of the generating units formerly owned by the SECV have been sold. Buyers are from within Australia and abroad. For example, on 21 May 1996, PowerGen, the second largest E\&W generating company, purchased a 49.9 percent share of Yallourn Energy, with the remaining shares purchased by investors from Japan and Australia. On 1 April 1997, Edison Mission Energy, a California-based U.S. firm, purchased the Loy Yang B station. On 4 August 1996, National Power, the largest E\&W generating company at that time, purchased a 52 percent share of Hazelwood Energy.

11. As of 13 December 1998, the first stage of the transition to a national electricity market for Australia, NEM1, ended. The operation of VicPool ceased, and responsibility for the management of the Victoria electricity market passed to the newly formed National Electricity Market Management Company (NEMMCO), which operates an integrated market between NSW, Victoria, Queensland, Australian Capital Territory, and South Australia. The current NEMMCO market rules are very similar to the final VicPool market rules described here. 
The distribution sector was formed into five privatized companies: CitiPower, Eastern Energy, PowerCor, Solaris Power, and United Energy, which are owned by a combination of U.S. utilities and Australian companies. For example, PowerCor is owned by the U.S. firm PacificCorp, and Eastern Energy is owned by Texas Utilities. There is an accounting separation within these distribution companies between their electricity distribution business and their electricity supply business. All other retailers have open and nondiscriminatory access to the wires of the other distribution companies.

The high-voltage transmission grid initially remained in state hands but was renamed PowerNet Victoria. In early 1998, it was sold to a U.S. energy services company GPU Inc. and renamed GPU PowerNet. The VPX is separate from all of these entities. Its mission is to manage the wholesale electricity market, manage the security of Victoria's power system, and direct the development of the high-voltage transmission system. This is different from the E\&W model, where NGC also owns the high-voltage transmission system in addition to providing these three services. It differs slightly from the Nord Pool model, where Stanett SF owns and operates the grid, but Nord Pool ASA, a subsidiary of Statnett SF, runs the wholesale electricity market.

The Victoria electricity supply industry is significantly smaller than either the E\&W or Norway and Sweden market. Peak demand in this market is approximately $7.5 \mathrm{GW}$, and the maximum amount of generating capacity that can be supplied to the market is approximately $9.0 \mathrm{GW}$. Because of this small peak demand, and despite the divestiture of SECV generation capacity to five firms, at least three of the largest baseload generators have sufficient generating capacity to supply at least 20 percent of this peak demand.

More than 80 percent of generating plant is brown coal fired, although some capacity does have fuel-switching capabilities. Brown coal has a high moisture content and a low sulfur and ash content, but also a very low heat content relative to black coal, which is used in the NSW market and the E\&W market. The brown coal power plants are located adjacent to large strip mines. Consequently, in spite of its low heat content, the very low cost of strip-mining brown coal makes these plants extremely low cost to operate. The operators of these facilities are also very reluctant to shut down these plants because more expensive fuels must be used to start them up.

The remaining generating capacity is shared equally between gas turbines and hydroelectric power. In this dimension, the market structure of the Victoria electricity supply industry is similar to the E\&W market structure, where there are two large, primarily coal-fired generation companies, National Power and PowerGen, which each control more than 25 percent of total $\mathrm{E} \& \mathrm{~W}$ system capacity. 


\subsubsection{Market Rules in the Victoria Power Exchange}

Although there are important differences, the VPX shares several features with the E\&W market. In particular, the VPX is a mandatory pool where prices are set on a half-hourly basis using bids submitted on a dayahead basis by generators and demand-side bidders. The rules governing the operation of the VPX have changed several times since the formation of the market in 1994. The latest phase is known as VicPool III enhanced. It commenced operation on 1 September 1996. Three major changes were made to the VicPool at this time. First, daily bidding by generators replaced weekly bidding. Second, more increments were added to the allowed bid functions that generators could submit. Formerly, generators were able to bid the capacity of each generating unit into the pool in only three increments (similar to the E\&W market), and up until the end of 1994 generators were only allowed to bid a single increment for each unit. In VicPool III enhanced, generators are able to bid prices for their units into the market in ten capacity increments that cannot be changed for the entire trading day-the twenty-four hour period beginning at 4 A.M. the following day. This rule is the same as the one in the E\&W market because in both markets generators cannot change the price bid for each increment for the entire day but they can vary the amount they are willing to supply from that capacity increment on a half-hourly basis.

A third change in the VicPool rules is that generators now must selfcommit their generation capacity. Previously, the VicPool operated on the basis of central commitment, similar to the E\&W system. Under central commitment, in their bids generators are required to submit start-up costs, start-up times, and minimum on and off times. NGC in E\&W (and formerly the VPX in Victoria) analyzes the costs and times presented by each generator and makes the start-up and shutdown decisions for all halfhours during the following day. Under VicPool III enhanced, generators are required to self-commit, which means that if a unit is committed by its owner, the capacity of the unit will be dispatched up to the point that the bid price for that capacity increment is less than the market-clearing price for that half-hour.

The other major difference between the VicPool and the E\&W pool is that the VicPool is very close to a real-time market. Prices paid to generators are based on a real-time forecast of the total system demand in the next five-minute interval. During each five-minute period in a given halfhour this demand forecast is crossed with the aggregate supply curve for that half-hour that can satisfy this demand forecast. Ramping constraints on generating units are respected in the five-minute-ahead dispatch process. If a unit willing to supply $100 \mathrm{MW}$ during a given half-hour at a certain price can only supply an additional $20 \mathrm{MW}$ with five minutes' notice because of ramping constraints, the price-setting process will move 
further up the aggregate supply curve for that half-hour to another unit to meet any remaining unmet demand. The five-minute price can only be set by a generator that is not constrained by its ramp rate during the next five minutes. The half-hourly price of electricity is then computed as the average of the six five-minute prices set during that half-hour. All energy produced during that hour is bought and sold at this ex post spot price. ${ }^{12}$ Longer horizon demand forecasts are used to schedule plant and make preliminary determinations of required ancillary services, such as reserve and reactive power, which are purchased under long-term contracts with generators. Because of the ex post nature of the VicPool there is no need for either a balancing market similar to that in Nord Pool or an UPLIFT charge as is the case in the E\&W pool.

A participant must not update or alter the self-commitment decision, the bid prices for each capacity band, or the elbows of the capacity bands for each unit bid after 11 A.M. on the day before this bid is active. The available capacity declaration for a unit during a half-hour cannot be altered for thirty-seven hours before the start of the day that contains that half-hour period, except to reflect a change in availability of the unit due to an event or events beyond the reasonable control of that participant, in order to reflect an unexpected increase in availability of the unit, and in response to a change in market conditions that the participant could not reasonably forecast.

Because half-hourly spot prices are determined after the half-hour period, it is not known whether supply will be sufficient to meet demand when bids are submitted on a day-ahead basis. If demand exceeds or is equal to total supply during a five-minute period, then the price is set equal to the value of lost load (VOLL), which is currently set equal to AU $\$ 5,000 / \mathrm{MWH}$.

There are several mechanisms for managing pool price risk in the VicPool. There is no formal futures market similar to the one that exists in Nord Pool. Generators and retailers can hedge against pool price volatility using two instruments: (1) vesting contracts and (2) contestable contracts. Each generator in the VicPool holds a vesting contract with at least one distributor. The vesting contracts cover consumption by franchise customers (those with no choice of electricity supplier) and large industrial customers on fixed-price contracts. The megawatt-hours covered under these contracts decline with the reduction in the size of the franchise market. The supply market becomes fully contestable (all customers can choose supply from any distributor) in December 2000 . These vesting contracts are essentially two-sided CFDs for pool prices below $\$ 300 / \mathrm{MWH}$ and onesided CFDs for pool price in excess of $\$ 300 / \mathrm{MWH}$. Contestable contracts

12. The basic features of this price-setting process are followed by NEMMCO, established 13 December 1998. 
are CFDs signed between generators and retailers to hedge the risks associated with supplying their contestable customers with electricity at prices that do not vary with the half-hourly changes in the pool price.

\subsubsection{Regulatory Oversight in the Victoria Electricity Supply Industry}

The Office of the Regulator General in Victoria is responsible for oversight of the Victoria electricity supply industry. It sets the prices for both transmission and distribution services, using a price-cap regulation plan. Because of the planned integration of the Australian electricity supply industry, recently there has been oversight at the national level of the VPX from the Australia Competition and Consumer Commission.

During the first two years of operation of the VPX, there were various inquiries into the exercise of market power because of sustained periods of high prices, despite a significant degree of volatility in these prices. Entry by new generators and changes in firm ownership as more new generating companies were formed from the sale of SECV units has led to much lower prices, but to an increase in relative volatility as measured by the ratio of the annual standard deviation to annual mean of VPX prices. Concern has died down about the exercise of market power in the Victoria electricity supply industry.

\subsection{The New Zealand Electricity Supply Industry}

Historically, the New Zealand electricity supply industry was dominated by a state-owned agency that operated the generation facilities and the bulk transmission network. Electricity supply authorities handled local distribution as local governing bodies (power boards) or under local body ownership (municipal electricity departments). This organizational structure continued largely unchanged until 1987, when the Electricity Division of the Ministry of Energy was restructured as the Electricity Corporation of New Zealand (ECNZ). At the same time, restrictions on entry into generation and wholesaling of electricity were removed. Because of excess capacity in generation, little entry took place. Despite being a stateowned enterprise, ECNZ was expected to earn a competitive rate of return on its assets. In 1988, ECNZ restructured itself into a corporate group with four subsidiaries: Production, Marketing, TransPower, and the PowerDesignBuild Group. TransPower owns and manages the national bulk transmission grid, and PowerDesignBuild offers consultancy and contracting services. At the present time ECNZ remains state owned, although eventual privatization has not been ruled out. Since 1992, TransPower has been a fully independent state-owned enterprise.

Reform of electricity distribution was spurred by the passage of the Energy Sector Reform Bill in 1992, which corporatized the electricity supply authorities and removed franchise areas, starting in 1993 for small 
customers, and for all customers in 1994. Ownership of the distribution network remained primarily in government hands as local governmentowned trusts or local government authorities, although some privatization has taken place and more is currently under way. Open-access nondiscriminatory tariffs must be set by all distribution companies, so that other electricity retailers can supply electricity to customers. The electricity distribution ("wires") business of each distribution company is separate from its competitive supply business.

\subsubsection{Market Structure in the New Zealand Electricity Industry}

The New Zealand electricity system consists of two alternating current subsystems, for North and South Islands, connected by a 1,200 MW underwater high-voltage direct current cable. All capacity on South Island is hydroelectric. There is sufficient capacity on South Island to serve its annual electricity requirements, as well as to export some power to North Island, where there is both hydroelectric and thermal capacity. Approximately 75 percent of North Island demand is met from hydroelectric sources, with the remaining 25 percent split between geothermal sources and fossil fuel (coal, natural gas, and oil) sources, with the fossil fuel generation (primarily from natural gas) approximately twice that of the geothermal. Annual electricity consumption for the entire country is approximately $30 \mathrm{TWH}$ per year, which is approximately one-tenth the annual consumption of England and Wales, despite the fact that the land area of New Zealand is approximately the same size as the United Kingdom. With approximately 3.5 million people in New Zealand, transmission and distribution accounts for a relatively large fraction of the cost of delivered electricity relative to the rest of the world, roughly 50 percent of the retail price of electricity.

An additional important aspect of the New Zealand system is that most of the population resides in the northern part of North Island, whereas most of the major hydroelectric resources are in the southern part of South Island. Consequently, transmission constraints between South Island and North Island can play an important role in the electricity supply process.

The generation side of the industry is dominated by the state-owned ECNZ, which prior to 1 February 1996 owned and operated more than 95 percent of total New Zealand electricity generating capacity. On 1 February 1996, in preparation for the formation of a wholesale market for electricity, Contact Energy Ltd. was formed as separate state-owned enterprise from ECNZ. It took over more than 30 percent of the generating capacity formerly owned and operated by ECNZ. ${ }^{13}$ The government also imposed a cap on new capacity by ECNZ until its generation market share

13. More recently, on 1 April 1999, ECNZ was separated into three state-owned generating entities-Gensis Power Ltd., Meridan Energy Ltd., and Mighty River Power Ltd. 
falls below 45 percent. It is also prohibited from owning any of the retail electricity companies. ECNZ was also required to offer a substantial fraction of its capacity in the form of "reasonably priced" CFDs. Several of the distribution companies own generating capacity, but none generates more than $250 \mathrm{GWH}$ annually. Despite the retention of state ownership of ECNZ and Contact Energy, the pattern of divestiture of generation from transmission and distribution for New Zealand follows that of the other three industries.

There are currently thirty-eight electricity distribution companies providing equal access distribution services and electricity supply to customers and one electricity retailer providing electricity supply only. The stateowned corporation TransPower owns and runs the bulk transmission grid. In this capacity it is also responsible for the purchase of ancillary services.

\subsubsection{Market Rules in the New Zealand Electricity Market}

On 1 October 1996, a wholesale electricity market in New Zealand commenced operation under the name Electricity Market Company (EMCO). This market is a true ex post spot market. Similar to the VicPool and Nord Pool, there is separation between the power exchange, which is run by EMCO, and the system operator, which is TransPower. Similar to the Nord Pool market structure, the wholesale electricity market is not mandatory. However, because of the concentration of generating assets in the hands of ECNZ and Contact Energy, the spot market trades a large fraction of the electricity sold in New Zealand.

Because of concerns about the capacity of the high-voltage cable between North and South Islands and the level of line losses along this link, spot prices are set at reference nodes in both North and South Islands. Generators submit offer functions giving the amount of capacity they are willing to supply as a function of the price for all half-hours during the following day for each generating unit. Each generating unit can have a maximum of five price bands, and all individual generating unit offer functions must be increasing in the offer price. Purchasers submit bid functions that are decreasing in the bid price and can contain up to ten price bands. Different from the markets in England and Wales and Australia, neither the price nor the quantity bands associated with the bid and offer functions can be altered for the duration that the bid or offer curve is valid. ${ }^{14}$ These offer and bid functions are used to perform a day-ahead prospective market, which results in a proposed dispatch schedule and forecast prices. Offer and bid functions may be freely changed up to four hours before

14. The price bands associated with bids and offers cannot be changed less than four hours prior to the trading period. However, if a bona fide physical reason exists, the quantity bands can be changed less than four hours prior to the trading period. However, the Market Surveillance Committee is notified of these quantity revisions and may rule on whether the revised bid was due to a bona fide physical reason. 
dispatch occurs. Dispatch must meet actual loads, but to the greatest extent possible it should also match the loads obtained by using a least cost dispatch based on the latest generator offers. Prices are determined after actual demand has been satisfied by resolving the market-clearing model to meet the actual metered load at each node using the generator offer curves as of the beginning of each half-hour trading period.

The New Zealand electricity supply industry uses a full nodal-pricing model, but with a direct current power flow approximation that uses piecewise linear line loss functions. Reserve capacity procurement is integrated into the market-clearing process. Joint reserve and energy offers made by generators are input into a single market-clearing linear programming problem to produce prices for energy at each node and two classes of reserve capacity in each island. Reed, Drayton-Bright, and Ring (1998) describe the operation of the reserve capacity portion of the spot market. Energy prices are set on a half-hourly basis at more than two hundred nodes, with approximately thirty of these nodes points where generators sell into the grid.

\subsubsection{Regulatory Oversight in the New Zealand Electricity Supply Industry}

There is no explicit regulation of the generation, transmission, or distribution sector, aside from monitoring by the New Zealand Ministry of Commerce. As noted earlier, the New Zealand government has taken a "light-handed" approach to regulation of the industry. Parties have been left to form arrangements among themselves, with all parties being free to appeal to the courts or the Commerce Commission. There is a Market Surveillance Committee that acts as an independent monitor of the market. The EMCO rules allow the Market Surveillance Committee to recommend rule changes, cancel rule changes, investigate misconduct and breaches of market rules, and discipline market participants for undesirable behavior. The committee can also impose fines on market participants for violations of the market rules or what it determines to be undesirable practices.

\subsection{An International Comparison of the Behavior of Spot Electricity Prices}

This section characterizes the time-series properties of the spot electricity prices from England and Wales, Norway and Sweden, Victoria, and New Zealand electricity markets since their inception. Our goal is to characterize several dimensions of the time-series behavior of prices in these four markets. Our ultimate goal is to relate differences in these dimensions of the behavior of electricity prices across the four markets to differences in market structure and market rules across the four markets. Although 
this is an extremely difficult task, the analysis to be presented does appear consistent with the view that market structure and market rules cause significant differences in the behavior of spot prices for electricity across the four markets.

One of the most striking features of prices from these electricity markets is their tremendous volatility within days and across days within the week. I would like to understand the extent to which this variability in prices is forecastable and how this forecastability varies across the four markets.

Table 3.1 gives the annual average half-hourly (hourly in the case of Nord Pool) price and standard deviation of price for each year in our sample in terms of the home currency of that country. For Nord Pool, prices are quoted in Norwegian kroner per megawatt-hour. The missing entries in the table are due to the fact that the electricity market did not operate during that year. For all markets, I only have data for a portion of the year in which the market began, and data for only the first few months of 1997. The E\&W market data run from 1 April 1990 to 31 March 1997. The Norwegian spot market data run from 4 May 1992 to 16 May 1997. The Victoria data begin 1 July 1994 and end 3 May 1997. The New Zealand data begin 1 October 1996 and end 31 May 1997.

Several conclusions are consistent with the results in table 3.1. First is that the mix of generation technology has an impact on both the mean and standard deviation of market prices. Prices in the two markets dominated by fossil fuel technology-E\&W and Victoria-tend to be much more volatile than prices in the two markets dominated by hydroelectric capacity - Nord Pool and New Zealand. The coefficient of variation, the standard deviation divided by the mean, for almost all years in E\&W and Victoria are larger than those in Nord Pool and New Zealand.

With the exception of Victoria in 1994 and 1995 versus 1996 and 1997 , mean prices in the fossil-fuel-dominated markets tend to be more stable across years than prices in the hydroelectric-dominated systems. ${ }^{15}$ Mean prices in the E\&W market are much more stable across the years than those in Nord Pool. As discussed above, a major determinant of the mean of prices in hydroelectric-capacity-dominated markets is the amount of water available. If there is little water, then reservoirs tend to be low and flow volumes in rivers are reduced, so that hydroelectric generators tend to be very reluctant to sell into the spot market during the winter season and spot prices remain high until the late spring and summer, when electricity demand is much lower. The supply of energy inputs to fossil-fuelbased systems is not nearly as sensitive to local weather conditions. Because there are relatively integrated international coal, natural gas, and oil

15. There are several reasons to believe that there was a regime shift in the VicPool before and after I January 1996. Before this date, very few of the generators had been sold off, so that the SECV was effectively bidding all plants. In addition, before this date, there were high levels of vesting contracts at prices between AU\$35/MWH and AU\$40/MWH. 


\section{Table 3.1 Annual Means and Standard Deviations of Spot Prices of Electricity}

\begin{tabular}{|c|c|c|c|c|c|c|c|c|c|c|}
\hline \multirow[b]{2}{*}{ Year } & \multicolumn{2}{|c|}{$E \& W$} & \multicolumn{2}{|c|}{ NW } & \multicolumn{2}{|c|}{ VIC } & \multicolumn{2}{|c|}{$\mathrm{NZN}$} & \multicolumn{2}{|c|}{ NZS } \\
\hline & Mean & SD & Mean & SD & Mean & SD & Mean & SD & Mean & SD \\
\hline 1990 & 17.38 & 5.38 & n.a. & n.a. & n.a. & n.a. & n.a. & n.a. & n.a. & n.a. \\
\hline 1991 & 22.50 & 12.65 & n.a. & n.a. & n.a. & n.a. & n.a. & n.a. & n.a. & n.a. \\
\hline 1992 & 23.42 & 6.28 & 58.10 & 44.38 & n.a. & n.a. & n.a. & n.a. & n.a. & n.a. \\
\hline 1993 & 27.14 & 7.86 & 80.28 & 41.02 & n.a. & n.a. & n.a. & n.a. & n.a. & n.a. \\
\hline 1994 & 24.73 & 18.73 & 182.67 & 49.29 & 36.72 & 18.24 & n.a. & n.a. & n.a. & n.a. \\
\hline 1995 & 26.15 & 50.89 & 117.69 & 38.92 & 41.94 & 30.02 & n.a. & n.a. & n.a. & n.a. \\
\hline 1996 & 25.18 & 27.85 & 253.52 & 44.62 & 21.11 & 19.30 & 39.36 & 17.00 & 28.53 & 6.53 \\
\hline 1997 & 29.27 & 27.97 & 150.63 & 42.90 & 22.96 & 59.05 & 46.97 & 8.71 & 41.97 & 8.87 \\
\hline
\end{tabular}

Note $: \mathrm{E} \& W=$ England and Wales Pool, units $=\mathrm{f} / \mathrm{MWH} ; \mathrm{NW}=$ Nord Pool, units $=$ NOK/MWH; VIC $=$ Victoria Power Exchange, units = AU\$ $/ \mathrm{MWH}$ NZN $=$ New Zealand North Island, units $=$ NZ\$/MWH; and NZS $=$ New Zealand South Island, units $=$ NZ\$/MWH. All prices in home currency per MWH. 
markets, prices for these fuels tend to be stable across years, so that the mean price of electricity from fossil-fuel-based markets should be stable across years. The more variable annual mean prices across years and smaller variance in prices within years in hydroelectric systems versus fossil-fuel-dominated systems is consistent with this view.

There are three alternative explanations for the lower level of volatility in Nord Pool and the NZEM relative to the E\&W market and the VicPool. First, both fossil-fuel-based systems, the E\&W market and the VicPool, are mandatory pools, whereas the two hydroelectric-based systems, Nord Pool and the NZEM, have optional day-ahead markets. Consequently, the lower relative volatility in Nord Pool and the NZEM could be explained by holders' of bilateral contracts for electricity standing ready to sell into the spot electricity market if prices become high enough. This willingness to sell into the spot market at high prices increases the elasticity of the supply response that any generating company might face if it attempts to raise its bid prices, so that much of the adjustment to high bids in the spot market will come in the form of reduced amounts transacted rather than increased prices, as is the case in mandatory pools with little, if any, demand-side bidding such as in the E\&W market, and to a lesser extent the VicPool.

A second explanation for the result in table 3.1 is that the vast majority of generating capacity in the E\&W market is privately owned and an increasing (over time) fraction of the capacity in the VicPool is privately owned, whereas both Nord Pool and the NZEM are dominated by large state-owned generation companies. One would expect the large stateowned companies to pursue other objectives besides maximizing profits, whereas the major goal of the privately owned firms would be to maximize profits. Therefore, some of the volatility in the E\&W market and the VicPool could be explained as episodes of successful and unsuccessful attempts to exercise market power. State-owned enterprises may also be unwilling to engage in the risky bidding behavior necessary to set these occasional high prices and may instead settle for lower but more certain revenue streams than privately owned firms.

A final explanation can be traced to the differences in the bidding process across the four markets. In the E\&W market and the VicPool generators can alter the quantity supplied from each bid increment on a halfhourly basis, whereas in Nord Pool and the New Zealand market both the prices and quantities associated with the hourly supply curves submitted by generators are fixed for the duration that a generating unit's supply curve is valid. The greater flexibility afforded to bidders in the E\&W market and the VicPool to vary their supply curves on a half-hourly basis may. allow generators to tailor their bids to set market prices that more closely follow the within-day pattern of total system load than in Nord Pool and the New Zealand market, where supply functions are generally fixed for longer periods of time during the day. 
A final aspect of table 3.1 deserves comment. Consistent with the description of the differences in market structure between North and South Islands in New Zealand-cheap, abundant hydroelectric power in South Island and most of the population in North Island along with more expensive fossil-fuel-based plants - the mean price in the north is significantly higher than the mean price in the south for both years. In addition, prices in the north are also more volatile than those in the south, particularly for 1996. This reflects the use of fossil units to meet system peaks in North Island. Consequently, even for an integrated system such as the New Zealand market, the region with the greater share of total electricity production from fossil fuel units experiences greater spot price volatility.

To determine which market sells electricity at the lowest price, I convert each hourly or half-hourly price to U.S. dollars using the relevant dollarto-home-currency exchange rate at noon that day obtained from the PACIFIC web site. ${ }^{16}$ Table 3.2 lists the mean and standard deviation of the half-hourly or hourly prices (in the case of Nord Pool) in U.S. dollars per megawatt-hour. The E\&W market consistently has the highest U.S. dollar price for electricity for the years in which I have comparable data. For both 1994 and 1995, the U.S. dollar prices in the E\&W market are significantly higher than those in Nord Pool or Victoria. In both of these years, Nord Pool set lower prices on average, although in 1996 and 1997, this order reverses, with VicPool U.S. dollar prices significantly lower than U.S. dollar prices in either Nord Pool or the NZEM. These low prices in Victoria can be explained in part by the extremely inexpensive Australian brown coal and natural gas purchased to generate electricity. The coal used to produce electricity in the $\mathrm{E} \& \mathrm{~W}$ market is considerably more expensive. U.K. coal is more costly to mine, and purchasing coal from abroad entails significant transportation costs, which increases its price in the E\&W market relative to Victoria.

In order to better understand the pattern of volatility in electricity prices in home currency per megawatt-hour in the four markets, I compute the ratio of the difference between the highest and lowest prices over a given time horizon divided by the average value of prices over that same time horizon. For example, for each day in the sample, I compute the difference between the highest and the lowest price for the day and divide that by the average price for that day. Repeating this calculation for each day in the sample for each market, and computing means, standard deviations, the sample minimum, and the sample maximum, yields the values given in table 3.3. This table shows that over all time horizons the prices in the E\&W market and the VicPool are considerably more variable than those

16. Policy Analysis and Computing and Information Facility in Commerce (PACIFIC) at the University of British Columbia, Faculty of Commerce and Business Administration (http://pacific.commerce.ubc.ca/xr/). 


\section{Table 3.2}

Annual Means and Standard Deviations of Spot Price of Electricity Converted to U.S. Dollars

\begin{tabular}{|c|c|c|c|c|c|c|c|c|c|c|}
\hline \multirow[b]{2}{*}{ Year } & \multicolumn{2}{|c|}{$E \& W$} & \multicolumn{2}{|c|}{ NW } & \multicolumn{2}{|c|}{ VIC } & \multicolumn{2}{|c|}{$\mathrm{NZN}$} & \multicolumn{2}{|c|}{ NZS } \\
\hline & Mean & SD & Mean & SD & Mean & SD & Mean & SD & Mean & SD \\
\hline 1990 & 31.84 & 10.25 & n.a. & n.a. & n.a. & n.a. & n.a. & n.a. & n.a. & n.a. \\
\hline 1991 & 39.80 & 22.71 & n.a. & n.a. & n.a. & n.a. & n.a. & n.a. & n.a. & n.a. \\
\hline 1992 & 41.32 & 11.31 & 9.20 & 6.73 & n.a. & n.a. & n.a. & n.a. & n.a. & n.a. \\
\hline 1993 & 40.80 & 11.91 & 11.28 & 5.62 & n.a. & n.a. & n.a. & n.a. & n.a. & n.a. \\
\hline 1994 & 38.00 & 29.37 & 25.97 & 7.04 & 27.42 & 13.65 & n.a. & n.a. & n.a. & n.a. \\
\hline 1995 & 41.10 & 79.15 & 18.50 & 5.89 & 30.95 & 21.94 & n.a. & n.a. & n.a. & n.a. \\
\hline 1996 & 39.37 & 44.06 & 39.26 & 6.86 & 16.53 & 15.03 & 27.77 & 11.93 & 20.13 & 4.59 \\
\hline 1997 & 47.96 & 46.95 & 22.50 & 7.14 & 17.83 & 46.00 & 32.75 & 6.04 & 29.25 & 6.10 \\
\hline
\end{tabular}

Note: Prices converted to U.S. dollars per megawatt-hour using daily exchange rates. See table 3.1 note for market abbreviations. 
Table 3.3 Ratio of Difference between Highest and Lowest Prices to Average Price over Various Time Horizons

\begin{tabular}{|c|c|c|c|c|}
\hline Horizon and Market & Mean & SD & Min & $\operatorname{Max}$ \\
\hline \multicolumn{5}{|l|}{ Day } \\
\hline NW & 0.18 & 0.19 & 0.00 & 2.04 \\
\hline $\mathrm{NZN}$ & 0.58 & 0.65 & 0.03 & 3.15 \\
\hline NZS & 0.37 & 0.41 & 0.01 & 2.86 \\
\hline$E \& W$ & 1.51 & 1.34 & 0.23 & 12.12 \\
\hline VIC & 1.78 & 1.45 & 0.03 & 26.58 \\
\hline \multicolumn{5}{|l|}{ Week } \\
\hline NW & 0.44 & 0.38 & 0.04 & 2.21 \\
\hline $\mathrm{NZN}$ & 1.49 & 1.04 & 0.23 & 3.31 \\
\hline NZS & 1.06 & 1.00 & 0.18 & 3.90 \\
\hline $\mathrm{E} \& W$ & 2.83 & 3.29 & 0.54 & 37.84 \\
\hline VIC & 3.97 & 8.51 & 0.80 & 102.22 \\
\hline \multicolumn{5}{|l|}{ Month } \\
\hline NW & 0.86 & 0.54 & 0.12 & 2.22 \\
\hline $\mathrm{NZN}$ & 2.66 & 1.06 & 0.66 & 4.09 \\
\hline NZS & 2.28 & 1.43 & 0.52 & 3.94 \\
\hline$E \& W$ & 5.23 & 6.53 & 0.89 & 45.08 \\
\hline VIC & 7.81 & 19.20 & 1.96 & 117.29 \\
\hline \multicolumn{5}{|l|}{ Fiscal year } \\
\hline NW & 2.48 & 0.99 & 1.14 & 4.00 \\
\hline NZN & n.a. & n.a. & n.a. & n.a. \\
\hline NZS & n.a. & n.a. & n.a. & n.a. \\
\hline E\&W & 18.80 & 15.26 & 4.07 & 46.37 \\
\hline VIC & 43.16 & 72.23 & 4.37 & 151.46 \\
\hline
\end{tabular}

Note $:$ Mean $=$ sample mean, $\mathrm{SD}=$ standard deviation, Min $=$ sample minimum, and Max $=$ sample maximum. See table 3.1 note for market abbreviations.

in Nord Pool and the NZEM. By this measure of variability, VicPool prices are more volatile than E\&W prices. Nord Pool prices exhibit the least amount of average variability over the four time horizons.

Because I do not have a complete year's worth of data for the NZEM, I cannot compute the ratio of the difference between the highest and lowest prices within the year divided by the average price for the year for NZEM prices. However, the greater variability in North Island versus South Island NZEM prices shows up in this measure of price variability for all available time horizons. Although the average variability of these prices is less than that magnitude in either the E\&W market or the VicPool, these prices are substantially more variable than Nord Pool prices. These results illustrate the differences in the time-series behavior of prices in systems where fossil fuels are used to meet peak demands as in North Island of New Zealand relative to systems where hydroelectric capacity is used to meet system peaks as in South Island of New Zealand and Nord Pool. 
The next step in the across-country analysis of the behavior of prices focuses on the relative forecastability of the daily vector of prices in each country. This requires a model for the time-series behavior of the $(48 \times 1)$ vector of half-hourly prices or $(24 \times 1)$ hourly prices for Nord Pool, which I denote $Y_{t}$. After some preliminary analysis of each vector of prices, I settled on a time-varying mean for $Y_{t}$ that depends on the day of the week and month of the sample period. I hypothesize that once $M_{v}$, the $(48 \times 1)$ ( $[24 \times 1]$ for the case of Nord Pool) vector of means of $Y_{t}$, is subtracted from $Y_{t}$, the resulting stochastic process is a vector autoregressive model of order 8 . The statistical model I hypothesize for $Y_{t}$ is

$$
\Phi(L)\left(Y_{t}-M_{\imath}\right)=E_{t},
$$

Where $E_{t}$ is a $(48 \times 1)([24 \times 1]$ for the case of Nord Pool) vector-valued white noise process with mean zero and covariance matrix $\Sigma, \Phi(L)=I$ $\Phi_{1} L-\cdots-\Phi_{p} L^{p}$, where each $\Phi_{i}$ is a $(48 \times 48)([24 \times 24]$ for the case of Nord Pool) matrix of coefficients and $L$ is the lag operator function defined by $Y_{t-k}=L^{k} Y_{t}$. The remaining discussion of the model is for case of forty-eight half-hourly prices, although the modifications necessary for twenty-four hourly prices are straightforward. Let $M_{t i}$ denote the $i$ th element of $M_{i}$. In terms of our above notation, $M_{t i}=X_{t}^{\prime} \beta_{i}$, where $X_{t}$ is a vector of day of the week and month indicator variables for load period $i$ and $\beta_{i}$ is the vector of coefficients associated with these indicator variables. Excluding the $\beta_{i}$ coefficients associated with $M_{t}$, for each element of $M_{t}$, there are $16,120=8 \times(48)^{2}$ elements of $\Phi_{1}, \Phi_{2}, \ldots, \Phi_{8}$ to estimate. Rather than present the more than 18,000 coefficient estimates (including the $\beta_{i}$ for each of the forty-eight load periods) for this model, which are estimated by least squares applied to each of the forty-eight load period price equations, I provide several summary measures of the adequacy of this model and summarize what insights it provides about the forecastability of $Y_{t}$ for each market.

To investigate the adequacy of equation (1) for each country, I compute the multivariate analogue of the Box-Pierce (1970) portmanteau statistic derived by Hosking $(1980)$ for the $(48 \times 1)$ vector of residuals from equation (1). This statistic is computed as

$$
P=T \sum_{r=1}^{M} \operatorname{trace}\left(C_{r}^{\prime} C_{0}^{-1} C_{r} C_{0}^{-1}\right), \quad \text { where } C_{r}=T^{-1} \sum_{t=r+1}^{T} \hat{E}_{t} \hat{E}_{t-r}^{\prime},
$$

where $\hat{E}_{t}$ is the residual vector from equation (1) for period $t$ and $C_{0}$ is the sample covariance matrix of $\hat{E}_{t}$. Hosking has shown that the asymptotic distribution of $P$ is $\chi^{2}$ with $N^{2} \times(M-p)$ degrees of freedom, where $p$ is the order of the autoregressive process and $N$ is the dimension of $Y_{t}$. For all of the models estimated, I find little evidence against the null hypothesis that $E_{t}$ is multivariate white noise. 
Table 3.4 presents the $R^{2}$, the standard error of the regression, and the mean of the dependent variable for each of forty-eight ordinary least squares regressions of the half-hourly price on eight lags of this price and all other half-hourly prices. I find the largest $R^{2}$-all in excess of $0.84-$ are associated with load periods 33 to 38 , which run from 4 P.M. to 7 P.M., the load periods in the day with highest prices on average as indicated by the sample mean of the PSP in each load period given in the third column. Load periods 33 to 38 are also the periods with the six largest estimated regression standard errors. The combination of these two results suggests that the explanatory power of the model is highest for those load periods $i=33, \ldots, 38$ with the highest unconditional variance in $Y_{t i}$. However, despite the superior explanatory power of the model for these load periods, the level of the estimated forecast variance is higher for these load periods than for any others. Past values of $Y_{t}$ therefore improve the predictive power of the load period regressions for periods 33 to 38 significantly more than they do for the other load period regressions, but despite this fact, these load periods are still the most unpredictable in terms of the estimated level of their day-ahead forecast variance. This result is consistent with the view that there are short periods within the day when the PSP is above or below its unconditional mean, and the occurrence of these extreme prices in certain load periods within a day make them more likely to occur in the same load periods in neighboring days.

Table 3.5 presents this same information for the $(24 \times 1)$ vector of daily Nord Pool spot prices. The most striking feature of this table is the uniformly high explanatory power of these twenty-four regressions. In all cases, the $R^{2}$ is at least 0.99 , which implies that almost all of the movements in hourly prices across days in Nord Pool can be forecast. In addition, none of the hours appear to be significantly more predictable using past prices than other hours. For all hours during the day, the standard errors of the regressions are very similar in magnitude, although the hours during the day with higher average prices do have slightly larger estimated residual variances.

Table 3.6 presents the information in table 3.4 for VicPool prices. The $R^{2}$ from the forty-eight regressions used to estimate the eighth-order vector autoregressive process indicate that VicPool prices are less forecastable than Nord Pool prices. The magnitude of the $R^{2}$ are similar to those for the $\mathrm{E} \& \mathrm{~W}$ system in table 3.4. However, different from the results in table 3.4 , I find that the higher average price periods do not have higher $R^{2}$ from the regression forecasting that price. In fact, the highest average price period, load period 26, has by far the lowest $R^{2}=0.44$. Different from the case of the E\&W market, the highest $R^{2}$ 's occur for load periods with both low and high average prices.

Because I only have a very short time series of prices for the NZEM, it is not possible to estimate an eighth-order vector autoregressive process 


\begin{tabular}{|c|c|c|c|}
\hline Load Period & $R^{2}$ & $\begin{array}{c}\text { Standard } \\
\text { Error of } \\
\text { Regression }\end{array}$ & $\begin{array}{c}\text { Sample Mean } \\
\text { Price } \\
\text { (£/MWH) }\end{array}$ \\
\hline 1 & 0.81 & 2.43 & 15.06 \\
\hline 2 & 0.78 & 3.91 & 17.32 \\
\hline 3 & 0.80 & 4.44 & 18.91 \\
\hline 4 & 0.80 & 4.77 & 19.92 \\
\hline 5 & 0.80 & 4.03 & 18.54 \\
\hline 6 & 0.80 & 3.91 & 17.96 \\
\hline 7 & 0.79 & 3.80 & 17.16 \\
\hline 8 & 0.79 & 3.10 & 15.78 \\
\hline 9 & 0.79 & 2.68 & 14.90 \\
\hline 10 & 0.83 & 2.21 & 14.42 \\
\hline 11 & 0.80 & 2.61 & 14.55 \\
\hline 12 & 0.82 & 2.45 & 14.56 \\
\hline 13 & 0.80 & 2.68 & 15.02 \\
\hline 14 & 0.80 & 3.49 & 17.66 \\
\hline 15 & 0.82 & 3.30 & 20.31 \\
\hline 16 & 0.76 & 4.55 & 22.15 \\
\hline 17 & 0.74 & 5.81 & 24.25 \\
\hline 18 & 0.72 & 6.52 & 25.96 \\
\hline 19 & 0.66 & 8.05 & 27.88 \\
\hline 20 & 0.66 & 8.57 & 29.45 \\
\hline 21 & 0.66 & 8.22 & 29.36 \\
\hline 22 & 0.66 & 8.10 & 28.60 \\
\hline 23 & 0.69 & 8.09 & 29.37 \\
\hline 24 & 0.69 & 8.93 & 30.99 \\
\hline 25 & 0.70 & 8.64 & 31.31 \\
\hline 26 & 0.70 & 7.73 & 29.71 \\
\hline 27 & 0.70 & 5.47 & 25.62 \\
\hline 28 & 0.71 & 4.65 & 23.65 \\
\hline 29 & 0.70 & 4.83 & 22.41 \\
\hline 30 & 0.73 & 4.56 & 21.83 \\
\hline 31 & 0.75 & 4.47 & 21.22 \\
\hline 32 & 0.79 & 7.69 & 22.97 \\
\hline 33 & 0.84 & 19.07 & 32.20 \\
\hline 34 & 0.86 & 31.34 & 44.61 \\
\hline 35 & 0.87 & 35.45 & 50.19 \\
\hline 36 & 0.87 & 28.72 & 46.24 \\
\hline 37 & 0.84 & 17.81 & 35.51 \\
\hline 38 & 0.85 & 9.10 & 30.24 \\
\hline 39 & 0.82 & 6.81 & 27.67 \\
\hline 40 & 0.81 & 4.97 & 25.52 \\
\hline 41 & 0.76 & 4.55 & 23.89 \\
\hline 42 & 0.75 & 4.29 & 23.91 \\
\hline 43 & 0.76 & 4.23 & 24.35 \\
\hline 44 & 0.79 & 4.05 & 24.10 \\
\hline 45 & 0.77 & 4.12 & 22.36 \\
\hline 46 & 0.77 & 3.75 & 19.85 \\
\hline 47 & 0.74 & 3.05 & 17.20 \\
\hline 48 & 0.78 & 2.52 & 15.43 \\
\hline
\end{tabular}


Table 3.5 $R^{2}$, Standard Error, and Sample Mean of Dependent Variable for Regression Forecasting Hourly Spot Price in Nord Pool

\begin{tabular}{cccc}
\hline Load Period & $R^{2}$ & $\begin{array}{c}\text { Standard } \\
\text { Error of } \\
\text { Regression }\end{array}$ & $\begin{array}{c}\text { Sample } \\
\text { Mean Price } \\
\text { (NOK/MWH) }\end{array}$ \\
\hline 1 & 0.99 & 7.31 & 137.99 \\
2 & 0.99 & 9.72 & 136.28 \\
3 & 0.99 & 8.87 & 135.38 \\
4 & 0.99 & 7.46 & 134.86 \\
5 & 0.99 & 7.40 & 135.05 \\
6 & 0.99 & 7.65 & 136.82 \\
7 & 0.99 & 8.84 & 142.69 \\
8 & 0.99 & 10.33 & 148.90 \\
9 & 0.99 & 10.72 & 151.05 \\
10 & 0.99 & 10.65 & 151.93 \\
11 & 0.99 & 10.17 & 151.87 \\
12 & 0.99 & 10.01 & 151.49 \\
13 & 0.99 & 9.41 & 149.57 \\
14 & 0.99 & 9.46 & 149.07 \\
15 & 0.99 & 9.39 & 148.76 \\
16 & 0.99 & 9.33 & 148.53 \\
17 & 0.99 & 9.03 & 148.00 \\
18 & 0.99 & 9.06 & 148.70 \\
19 & 0.99 & 8.92 & 148.98 \\
20 & 0.99 & 8.69 & 148.41 \\
21 & 0.99 & 8.44 & 147.81 \\
22 & 0.99 & 8.48 & 147.69 \\
23 & 0.99 & 7.99 & 145.43 \\
24 & 0.99 & 10.01 & 141.79 \\
\hline
\end{tabular}

for these prices. I estimate the vector autoregression with the largest number of lags possible given the time series of prices available to me. In this case, I am able to estimate a fourth-order vector autoregressive process. Table 3.7 presents the $R^{2}$, the standard error of the regression, and the mean of the dependent variable for each of forty-eight ordinary least squares regressions of the half-hourly spot price on four lags of this price and all other half-hourly prices for North Island spot prices. Table 3.8 produces the same information for South Island spot prices. The South Island price results resemble the results for Nord Pool, consistent with the fact that South Island is dominated by hydroelectric capacity. The North Island results resemble the Nord Pool results, but they show more variability across hours in the $R^{2}$ and the standard errors of the regression than do the South Island results. This is consistent with the use of fossil fuel plants in North Island.

A final issue associated with the $Y_{t}$ process is the extent to which fortyeight (twenty-four in the case of Nord Pool) distinct prices occur within 


\begin{tabular}{|c|c|c|c|}
\hline Load Period & $R^{2}$ & $\begin{array}{l}\text { Standard } \\
\text { Error of } \\
\text { Regression }\end{array}$ & $\begin{array}{c}\text { Sample } \\
\text { Mean Price } \\
\text { (AU\$/MWH) }\end{array}$ \\
\hline 1 & 0.89 & 9.23 & 32.22 \\
\hline 2 & 0.89 & 9.12 & 29.06 \\
\hline 3 & 0.87 & 10.49 & 33.47 \\
\hline 4 & 0.87 & 9.72 & 29.36 \\
\hline 5 & 0.87 & 8.59 & 24.82 \\
\hline 6 & 0.86 & 7.77 & 20.92 \\
\hline 7 & 0.86 & 7.15 & 17.40 \\
\hline 8 & 0.84 & 6.94 & 14.73 \\
\hline 9 & 0.83 & 6.34 & 12.85 \\
\hline 10 & 0.80 & 6.64 & 11.95 \\
\hline 11 & 0.77 & 9.10 & 13.69 \\
\hline 12 & 0.78 & 9.51 & 16.28 \\
\hline 13 & 0.79 & 11.16 & 22.35 \\
\hline 14 & 0.81 & 13.29 & 28.56 \\
\hline 15 & 0.84 & 11.35 & 29.47 \\
\hline 16 & 0.85 & 13.39 & 34.02 \\
\hline 17 & 0.83 & 14.97 & 36.46 \\
\hline 18 & 0.82 & 16.37 & 37.00 \\
\hline 19 & 0.84 & 15.55 & 37.81 \\
\hline 20 & 0.84 & 15.71 & 38.03 \\
\hline 21 & 0.85 & 15.43 & 37.99 \\
\hline 22 & 0.85 & 16.08 & 38.19 \\
\hline 23 & 0.84 & 15.93 & 37.38 \\
\hline 24 & 0.87 & 15.06 & 37.26 \\
\hline 25 & 0.89 & 16.56 & 37.50 \\
\hline 26 & 0.44 & 113.75 & 40.80 \\
\hline 27 & 0.81 & 18.47 & 38.20 \\
\hline 28 & 0.81 & 18.39 & 37.86 \\
\hline 29 & 0.80 & 18.73 & 37.21 \\
\hline 30 & 0.78 & 18.80 & 36.31 \\
\hline 31 & 0.79 & 18.03 & 35.90 \\
\hline 32 & 0.79 & 18.77 & 35.92 \\
\hline 33 & 0.80 & 17.62 & 35.76 \\
\hline 34 & 0.79 & 17.22 & 36.15 \\
\hline 35 & 0.80 & 17.49 & 37.59 \\
\hline 36 & 0.82 & 17.55 & 39.92 \\
\hline 37 & 0.77 & 21.82 & 39.84 \\
\hline 38 & 0.81 & 18.28 & 38.08 \\
\hline 39 & 0.84 & 14.66 & 35.50 \\
\hline 40 & 0.81 & 14.64 & 34.39 \\
\hline 41 & 0.86 & 14.24 & 33.80 \\
\hline 42 & 0.86 & 13.85 & 32.33 \\
\hline 43 & 0.83 & 13.26 & 29.87 \\
\hline 44 & 0.83 & 12.28 & 26.52 \\
\hline 45 & 0.82 & 12.09 & 25.21 \\
\hline 46 & 0.80 & 12.08 & 24.74 \\
\hline 47 & 0.79 & 14.60 & 34.18 \\
\hline 48 & 0.80 & 13.76 & 33.31 \\
\hline
\end{tabular}


Table 3.7

$R^{2}$, Standard Error, and Sample Mean of Dependent Variable for Regression Forecasting Half-Hourly Spot Prices in NZEM-North Island Reference Node

\begin{tabular}{|c|c|c|c|}
\hline Load Period & $R^{2}$ & $\begin{array}{c}\text { Standard } \\
\text { Error of } \\
\text { Regression }\end{array}$ & $\begin{array}{c}\text { Sample } \\
\text { Mean Price } \\
(\mathrm{NZ} \$ / \mathrm{MWH})\end{array}$ \\
\hline 1 & 0.98 & 4.06 & 42.55 \\
\hline 2 & 0.98 & 4.22 & 41.71 \\
\hline 3 & 0.97 & 4.19 & 41.09 \\
\hline 4 & 0.97 & 4.26 & 40.54 \\
\hline 5 & 0.97 & 4.14 & 39.61 \\
\hline 6 & 0.97 & 3.85 & 38.71 \\
\hline 7 & 0.96 & 4.48 & 38.42 \\
\hline 8 & 0.97 & 3.90 & 38.08 \\
\hline 9 & 0.97 & 4.20 & 37.87 \\
\hline 10 & 0.97 & 4.19 & 38.03 \\
\hline 11 & 0.96 & 4.19 & 38.28 \\
\hline 12 & 0.96 & 4.12 & 38.80 \\
\hline 13 & 0.96 & 3.91 & 40.11 \\
\hline 14 & 0.96 & 4.23 & 42.31 \\
\hline 15 & 0.96 & 7.20 & 45.34 \\
\hline 16 & 0.97 & 10.50 & 50.84 \\
\hline 17 & 0.96 & 11.02 & 50.33 \\
\hline 18 & 0.95 & 11.57 & 49.27 \\
\hline 19 & 0.97 & 6.43 & 47.35 \\
\hline 20 & 0.96 & 7.33 & 47.04 \\
\hline 21 & 0.98 & 4.84 & 46.46 \\
\hline 22 & 0.97 & 5.19 & 46.30 \\
\hline 23 & 0.97 & 5.30 & 46.22 \\
\hline 24 & 0.96 & 6.56 & 46.76 \\
\hline 25 & 0.96 & 6.30 & 46.14 \\
\hline 26 & 0.97 & 5.22 & 46.10 \\
\hline 27 & 0.96 & 4.45 & 45.30 \\
\hline 28 & 0.97 & 4.38 & 45.36 \\
\hline 29 & 0.97 & 5.06 & 45.14 \\
\hline 30 & 0.98 & 5.00 & 45.32 \\
\hline 31 & 0.97 & 5.32 & 45.24 \\
\hline 32 & 0.96 & 7.54 & 46.42 \\
\hline 33 & 0.93 & 11.18 & 46.17 \\
\hline 34 & 0.97 & 7.46 & 47.67 \\
\hline 35 & 0.94 & 9.36 & 47.08 \\
\hline 36 & 0.92 & 10.06 & 47.55 \\
\hline 37 & 0.95 & 7.49 & 46.60 \\
\hline 38 & 0.95 & 6.19 & 45.90 \\
\hline 39 & 0.96 & 5.35 & 45.33 \\
\hline 40 & 0.97 & 4.61 & 45.03 \\
\hline 41 & 0.98 & 6.38 & 47.00 \\
\hline 42 & 0.98 & 6.80 & 47.53 \\
\hline 43 & 0.98 & 5.19 & 46.35 \\
\hline 44 & 0.98 & 5.15 & 46.03 \\
\hline 45 & 0.96 & 4.33 & 43.63 \\
\hline 46 & 0.97 & 3.76 & 42.32 \\
\hline 47 & 0.97 & 5.07 & 43.44 \\
\hline 48 & 0.96 & 5.92 & 41.59 \\
\hline
\end{tabular}




\begin{tabular}{|c|c|c|c|}
\hline Load Period & $R^{2}$ & $\begin{array}{l}\text { Standard } \\
\text { Error of } \\
\text { Regression }\end{array}$ & $\begin{array}{c}\text { Sample } \\
\text { Mean Price } \\
\text { (NZ\$/MWH) }\end{array}$ \\
\hline 1 & 0.99 & 3.13 & 37.40 \\
\hline 2 & 0.99 & 2.86 & 36.95 \\
\hline 3 & 0.99 & 2.88 & 36.48 \\
\hline 4 & 0.99 & 3.16 & 36.09 \\
\hline 5 & 0.99 & 3.04 & 35.23 \\
\hline 6 & 0.99 & 3.07 & 34.48 \\
\hline 7 & 0.98 & 3.39 & 33.87 \\
\hline 8 & 0.98 & 3.39 & 33.54 \\
\hline 9 & 0.98 & 3.48 & 33.32 \\
\hline 10 & 0.98 & 3.78 & 33.30 \\
\hline 11 & 0.98 & 3.30 & 33.34 \\
\hline 12 & 0.99 & 2.75 & 33.66 \\
\hline 13 & 0.99 & 2.78 & 34.74 \\
\hline 14 & 0.98 & 3.56 & 36.33 \\
\hline 15 & 0.98 & 4.89 & 37.98 \\
\hline 16 & 0.96 & 7.59 & 39.73 \\
\hline 17 & 0.97 & 5.35 & 38.81 \\
\hline 18 & 0.96 & 5.48 & 38.85 \\
\hline 19 & 0.99 & 3.21 & 38.98 \\
\hline 20 & 0.98 & 3.22 & 39.01 \\
\hline 21 & 0.98 & 3.43 & 39.16 \\
\hline 22 & 0.98 & 3.46 & 39.17 \\
\hline 23 & 0.98 & 3.30 & 39.13 \\
\hline 24 & 0.98 & 3.48 & 39.34 \\
\hline 25 & 0.98 & 3.35 & 39.25 \\
\hline 26 & 0.99 & 3.00 & 39.03 \\
\hline 27 & 0.99 & 2.93 & 39.21 \\
\hline 28 & 0.99 & 3.03 & 38.97 \\
\hline 29 & 0.99 & 3.12 & 38.56 \\
\hline 30 & 0.98 & 3.28 & 38.26 \\
\hline 31 & 0.98 & 3.33 & 38.29 \\
\hline 32 & 0.98 & 3.26 & 38.71 \\
\hline 33 & 0.98 & 3.36 & 38.90 \\
\hline 34 & 0.99 & 3.05 & 39.05 \\
\hline 35 & 0.97 & 5.53 & 39.56 \\
\hline 36 & 0.96 & 6.38 & 40.19 \\
\hline 37 & 0.99 & 3.56 & 39.60 \\
\hline 38 & 0.99 & 3.38 & 39.19 \\
\hline 39 & 0.99 & 3.22 & 38.85 \\
\hline 40 & 0.99 & 2.83 & 38.28 \\
\hline 41 & 0.99 & 3.16 & 38.07 \\
\hline 42 & 0.98 & 3.74 & 37.94 \\
\hline 43 & 0.98 & 4.13 & 37.90 \\
\hline 44 & 0.98 & 4.02 & 38.03 \\
\hline 45 & 0.98 & 3.87 & 37.52 \\
\hline 46 & 0.98 & 3.43 & 36.62 \\
\hline 47 & 0.98 & 3.64 & 37.31 \\
\hline 48 & 0.98 & 3.60 & 36.21 \\
\hline
\end{tabular}


the day. Specifically, are there really forty-eight distinct sources of stochastic variation in prices over the course of the day? The way I address this question is by asking if $E_{t}$ possesses a factor structure. By this I mean that $E_{1}$ can be written as

$$
E_{t}=\Delta V_{t}+U_{t},
$$

where $\Delta$ is a $48 \times G(G<48)$ matrix, $V$, is a $(G \times 1)$ white noise process with mean zero and covariance matrix $I_{G}$ (the identity matrix of dimension $G)$, and $U_{t}$ is a $(48 \times 48)$ white noise process with mean zero and covariance matrix $\sigma^{2} I$, where $I$ is a $(48 \times 48)$ identity matrix. The processes $V_{t}$ and $U_{t}$ are assumed to be uncorrelated. This structure imposes restrictions on the form of the covariance matrix of $\Sigma$. In general there are (1/2) $(48)(49)=1,176$ distinct elements of $\Sigma$. For example, if $I$ assume that $G$, the number of common factors, equals one, then there are forty-eight elements of $\Delta$ and $\sigma^{2}$, which implies that the 1,176 elements of $\Sigma$ can be written as functions of the forty-eight elements of $\Delta$ and $\sigma^{2}$, which implies a significant number of restrictions. The usual way to determine the extent to which there exists a factor structure for $E_{t}$ is to compute the principal components of $\Sigma$ and the eigenvalues associated with these principal components. Defining trace $(\Sigma)$ as the total variation in $\Sigma$, by the properties of the trace operator, the sum of the eigenvalues of $\Sigma$ equals trace $(\Sigma)$. Consequently, I can get a measure of the extent to which a single principal component or group of orthogonal principal components explains the total variation in $\Sigma$. (Another definition often used is the determinant of $\Sigma$ (det $(\Sigma))$ because $\operatorname{det}(\Sigma)$ is the product of the eigenvalues. This would involve computing the ratio of the determinant to the product of a subset of the eigenvalues.) In table 3.9, I list the eigenvalues associated with the fortyeight principal components of the white noise process driving the vector of daily E\&W prices. The last column computes the cumulative sum of the eigenvalues up to the number of principal components for that row divided by the trace of $\Sigma$. This table indicates that more than 20 percent of the total variation is explained by the first principal component. However, the number of factors necessary to adequately model the structure of $\Sigma$ appears to be large. For example, the cumulative number of principal components necessary to capture 90 percent of the total variation in $\Sigma$ is twenty-two. The large number of factors necessary to represent a substantial fraction of the total variation in $\Sigma$ is consistent with the view that there is not a single or even a small number of independent determinants of the pattern of spot prices within the day in the E\&W market.

Table 3.10 repeats this calculation for the $(24 \times 1)$ covariance matrix of the white noise process driving Nord Pool spot prices. This table is very different from the one for $E \& W$ prices. Over 75 percent of the total variation in $\Sigma$ is explained by the first principal component. It only takes three 


\begin{tabular}{|c|c|c|}
\hline $\begin{array}{l}\text { Principal } \\
\text { Component }\end{array}$ & Eigenvalue & $\begin{array}{l}\text { Percentage of } \\
\text { Total Variance }\end{array}$ \\
\hline 1 & 12.267 & 0.2556 \\
\hline 2 & 4.861 & 0.3568 \\
\hline 3 & 3.926 & 0.4386 \\
\hline 4 & 2.684 & 0.4945 \\
\hline 5 & 2.399 & 0.5445 \\
\hline 6 & 2.119 & 0.5887 \\
\hline 7 & 1.684 & 0.6283 \\
\hline 8 & 1.652 & 0.6582 \\
\hline 9 & 1.552 & 0.6905 \\
\hline 10 & 1.401 & 0.7197 \\
\hline 11 & 1.108 & 0.7428 \\
\hline 12 & 1.096 & 0.7656 \\
\hline 13 & 1.021 & 0.7869 \\
\hline 14 & 0.838 & 0.8044 \\
\hline 15 & 0.772 & 0.8204 \\
\hline 16 & 0.720 & 0.8355 \\
\hline 17 & 0.685 & 0.8497 \\
\hline 18 & 0.540 & 0.8610 \\
\hline 19 & 0.502 & 0.8714 \\
\hline 20 & 0.481 & 0.8814 \\
\hline 21 & 0.462 & 0.8911 \\
\hline 22 & 0.423 & 0.9000 \\
\hline 23 & 0.420 & 0.9086 \\
\hline 24 & 0.394 & 0.9168 \\
\hline 25 & 0.385 & 0.9248 \\
\hline 26 & 0.355 & 0.9322 \\
\hline 27 & 0.326 & 0.9390 \\
\hline 28 & 0.307 & 0.9454 \\
\hline 29 & 0.273 & 0.9511 \\
\hline 30 & 0.253 & 0.9564 \\
\hline 31 & 0.242 & 0.9614 \\
\hline 32 & 0.228 & 0.9661 \\
\hline 33 & 0.206 & 0.9705 \\
\hline 34 & 0.182 & 0.9743 \\
\hline 35 & 0.161 & 0.9776 \\
\hline 36 & 0.147 & 0.9807 \\
\hline 37 & 0.143 & 0.9836 \\
\hline 38 & 0.129 & 0.9863 \\
\hline 39 & 0.115 & 0.9887 \\
\hline 40 & 0.110 & 0.9910 \\
\hline 41 & 0.096 & 0.9930 \\
\hline 42 & 0.088 & 0.9950 \\
\hline 43 & 0.086 & 0.9966 \\
\hline 44 & 0.053 & 0.9978 \\
\hline 45 & 0.049 & 0.9988 \\
\hline 46 & 0.038 & 0.9996 \\
\hline 47 & 0.014 & 0.9998 \\
\hline 48 & 0.007 & 1.0000 \\
\hline
\end{tabular}


Table 3.10 Eigenvalues of Residual Covariance Matrix from Vector Autoregressive Model Used to Forecast Vector of Daily Spot Prices in Nord Pool

\begin{tabular}{lcc}
\hline Principal & Eigenvalue & $\begin{array}{c}\text { Percentage of } \\
\text { Total Variation }\end{array}$ \\
\hline 1 & 18.089 & 0.7537 \\
2 & 2.795 & 0.8702 \\
3 & 0.757 & 0.9017 \\
4 & 0.481 & 0.9218 \\
5 & 0.412 & 0.9389 \\
6 & 0.328 & 0.9526 \\
7 & 0.253 & 0.9632 \\
8 & 0.197 & 0.9714 \\
9 & 0.154 & 0.9778 \\
10 & 0.122 & 0.9829 \\
11 & 0.100 & 0.9871 \\
12 & 0.064 & 0.9897 \\
13 & 0.060 & 0.9923 \\
14 & 0.050 & 0.9944 \\
15 & 0.040 & 0.9960 \\
16 & 0.023 & 0.9970 \\
17 & 0.017 & 0.9977 \\
18 & 0.013 & 0.9982 \\
19 & 0.012 & 0.9987 \\
20 & 0.011 & 0.9991 \\
21 & 0.009 & 0.9995 \\
22 & 0.006 & 0.9998 \\
23 & 0.003 & 0.9999 \\
24 & 0.002 & 1.0000 \\
\hline & &
\end{tabular}

factors to explain more than 90 percent of the total variation in $\Sigma$. This factor structure is consistent with the view discussed earlier that there is a single dominant determinant of unexpectedly high prices within a day, uncertainly about the availability of future water supplies.

Table 3.11 presents the forty-eight eigenvalues of the estimate of $\Sigma$ for VicPool prices. The story that emerges is midway between the one from Nord Pool and the one from the E\&W market. Approximately half of the total variation in $\Sigma$ is explained by the first principal component. Only fifteen factors, versus twenty-two in the E\&W market, are required to explain more than 90 percent of the total variation in $\Sigma$.

Tables 3.12 and 3.13 present the forty-eight eigenvalues of the estimate of $\Sigma$ for North Island and South Island prices, respectively. Consistent with North Island use of fossil units, the number of eigenvalues necessary to explain 90 percent of the variation in $\Sigma$ is ten. Whereas for South Island this number is eight, which is consistent with it being a hydro-based system where the opportunity cost of water is the primary determinant of price movements within and across days. 
Table 3.11 Eigenvalues of Residual Covariance Matrix from Vector Autoregressive Model Used to Forecast Vector of Daily Spot Prices in VicPool

\begin{tabular}{|c|c|c|}
\hline $\begin{array}{l}\text { Principal } \\
\text { Component }\end{array}$ & Eigenvalue & $\begin{array}{l}\text { Percentage of } \\
\text { Total Variation }\end{array}$ \\
\hline 1 & 23.405 & 0.4876 \\
\hline 2 & 4.694 & 0.5854 \\
\hline 3 & 3.231 & 0.6527 \\
\hline 4 & 2.208 & 0.6987 \\
\hline 5 & 1.829 & 0.7368 \\
\hline 6 & 1.433 & 0.7667 \\
\hline 7 & 1.254 & 0.7928 \\
\hline 8 & 0.927 & 0.8121 \\
\hline 9 & 0.898 & 0.8308 \\
\hline 10 & 0.785 & 0.8472 \\
\hline 11 & 0.711 & 0.8620 \\
\hline 12 & 0.567 & 0.8738 \\
\hline 13 & 0.511 & 0.8844 \\
\hline 14 & 0.480 & 0.8944 \\
\hline 15 & 0.439 & 0.9036 \\
\hline 16 & 0.381 & 0.9115 \\
\hline 17 & 0.344 & 0.9187 \\
\hline 18 & 0.299 & 0.9249 \\
\hline 19 & 0.284 & 0.9308 \\
\hline 20 & 0.262 & 0.9363 \\
\hline 21 & 0.255 & 0.9416 \\
\hline 22 & 0.236 & 0.9465 \\
\hline 23 & 0.208 & 0.9508 \\
\hline 24 & 0.190 & 0.9548 \\
\hline 25 & 0.187 & 0.9587 \\
\hline 26 & 0.183 & 0.9625 \\
\hline 27 & 0.158 & 0.9658 \\
\hline 28 & 0.145 & 0.9688 \\
\hline 29 & 0.133 & 0.9716 \\
\hline 30 & 0.124 & 0.9742 \\
\hline 31 & 0.123 & 0.9767 \\
\hline 32 & 0.120 & 0.9793 \\
\hline 33 & 0.100 & 0.9813 \\
\hline 34 & 0.099 & 0.9834 \\
\hline 35 & 0.088 & 0.9852 \\
\hline 36 & 0.085 & 0.9870 \\
\hline 37 & 0.078 & 0.9886 \\
\hline 38 & 0.072 & 0.9901 \\
\hline 39 & 0.070 & 0.9916 \\
\hline 40 & 0.066 & 0.9929 \\
\hline 41 & 0.060 & 0.9942 \\
\hline 42 & 0.052 & 0.9953 \\
\hline 43 & 0.050 & 0.9963 \\
\hline 44 & 0.044 & 0.9973 \\
\hline 45 & 0.042 & 0.9981 \\
\hline 46 & 0.034 & 0.9988 \\
\hline 47 & 0.029 & 0.9995 \\
\hline 48 & 0.026 & 1.0000 \\
\hline
\end{tabular}


Table 3.12

Eigenvalues of Residual Covariance Matrix from Vector Autoregressive Model Used to Forecast Vector of Daily Pool Selling Price in NZEM-North Island Reference Node

\begin{tabular}{|c|c|c|}
\hline $\begin{array}{l}\text { Principal } \\
\text { Component }\end{array}$ & Eigenvalue & $\begin{array}{l}\text { Percentage of } \\
\text { Total Variance }\end{array}$ \\
\hline 1 & 19.026 & 0.3964 \\
\hline 2 & 9.216 & 0.5584 \\
\hline 3 & 3.458 & 0.6604 \\
\hline 4 & 3.151 & 0.7261 \\
\hline 5 & 2.920 & 0.7869 \\
\hline 6 & 1.729 & 0.8229 \\
\hline 7 & 1.465 & 0.8535 \\
\hline 8 & 1.090 & 0.8762 \\
\hline 9 & 0.958 & 0.8961 \\
\hline 10 & 0.764 & 0.9120 \\
\hline 11 & 0.671 & 0.9260 \\
\hline 12 & 0.565 & 0.9378 \\
\hline 13 & 0.553 & 0.9493 \\
\hline 14 & 0.478 & 0.9593 \\
\hline 15 & 0.324 & 0.9660 \\
\hline 16 & 0.305 & 0.9724 \\
\hline 17 & 0.261 & 0.9778 \\
\hline 18 & 0.198 & 0.9819 \\
\hline 19 & 0.167 & 0.9854 \\
\hline 20 & 0.137 & 0.9883 \\
\hline 21 & 0.110 & 0.9906 \\
\hline 22 & 0.096 & 0.9925 \\
\hline 23 & 0.084 & 0.9943 \\
\hline 24 & 0.063 & 0.9956 \\
\hline 25 & 0.047 & 0.9966 \\
\hline 26 & 0.046 & 0.9975 \\
\hline 27 & 0.032 & 0.9982 \\
\hline 28 & 0.029 & 0.9988 \\
\hline 29 & 0.021 & 0.9992 \\
\hline 30 & 0.016 & 0.9996 \\
\hline 31 & 0.010 & 0.9998 \\
\hline 32 & 0.006 & 0.9999 \\
\hline 33 & 0.004 & 1.0000 \\
\hline 34 & 0.000 & 1.0000 \\
\hline 35 & 0.000 & 1.0000 \\
\hline 36 & 0.000 & 1.0000 \\
\hline 37 & 0.000 & 1.0000 \\
\hline 38 & 0.000 & 1.0000 \\
\hline 39 & 0.000 & 1.0000 \\
\hline 40 & 0.000 & 1.0000 \\
\hline 41 & 0.000 & 1.0000 \\
\hline 42 & 0.000 & 1.0000 \\
\hline 43 & 0.000 & 1.0000 \\
\hline 44 & 0.000 & 1.0000 \\
\hline 45 & 0.000 & 1.0000 \\
\hline 46 & 0.000 & 1.0000 \\
\hline 47 & 0.000 & 1.0000 \\
\hline 48 & 0.000 & 1.0000 \\
\hline
\end{tabular}


Table 3.13 Eigenvalues of Residual Covariance Matrix from Vector Autoregressive Model Used to Forecast Vector of Daily Pool Selling Price in NZEM-South Island Reference Node

\begin{tabular}{|c|c|c|}
\hline $\begin{array}{l}\text { Principal } \\
\text { Component }\end{array}$ & Eigenvalue & $\begin{array}{l}\text { Percentage of } \\
\text { Total Variance }\end{array}$ \\
\hline 1 & 22.101 & 0.4604 \\
\hline 2 & 9.271 & 0.6536 \\
\hline 3 & 4.255 & 0.7422 \\
\hline 4 & 2.379 & 0.7918 \\
\hline 5 & 1.834 & 0.8300 \\
\hline 6 & 1.761 & 0.8667 \\
\hline 7 & 1.076 & 0.8891 \\
\hline 8 & 1.055 & 0.9111 \\
\hline 9 & 0.723 & 0.9262 \\
\hline 10 & 0.639 & 0.9395 \\
\hline 11 & 0.546 & 0.9508 \\
\hline 12 & 0.369 & 0.9585 \\
\hline 13 & 0.319 & 0.9651 \\
\hline 14 & 0.267 & 0.9707 \\
\hline 15 & 0.245 & 0.9758 \\
\hline 16 & 0.207 & 0.9801 \\
\hline 17 & 0.171 & 0.9837 \\
\hline 18 & 0.118 & 0.9861 \\
\hline 19 & 0.110 & 0.9884 \\
\hline 20 & 0.094 & 0.9904 \\
\hline 21 & 0.081 & 0.9921 \\
\hline 22 & 0.076 & 0.9937 \\
\hline 23 & 0.061 & 0.9949 \\
\hline 24 & 0.051 & 0.9960 \\
\hline 25 & 0.043 & 0.9969 \\
\hline 26 & 0.039 & 0.9977 \\
\hline 27 & 0.033 & 0.9984 \\
\hline 28 & 0.027 & 0.9990 \\
\hline 29 & 0.018 & 0.9993 \\
\hline 30 & 0.013 & 0.9996 \\
\hline 31 & 0.010 & 0.9998 \\
\hline 32 & 0.005 & 0.9999 \\
\hline 33 & 0.003 & 1.0000 \\
\hline 34 & 0.000 & 1.0000 \\
\hline 35 & 0.000 & 1.0000 \\
\hline 36 & 0.000 & 1.0000 \\
\hline 37 & 0.000 & 1.0000 \\
\hline 38 & 0.000 & 1.0000 \\
\hline 39 & 0.000 & 1.0000 \\
\hline 40 & 0.000 & 1.0000 \\
\hline 41 & 0.000 & 1.0000 \\
\hline 42 & 0.000 & 1.0000 \\
\hline 43 & 0.000 & 1.0000 \\
\hline 44 & 0.000 & 1.0000 \\
\hline 45 & 0.000 & 1.0000 \\
\hline 46 & 0.000 & 1.0000 \\
\hline 47 & 0.000 & 1.0000 \\
\hline 48 & 0.000 & 1.0000 \\
\hline
\end{tabular}


Several overall conclusions emerge from tables 3.4 through 3.13 . The dynamics of the within-day variation in prices in the $\mathrm{E} \& \mathrm{~W}$ market is more complex than the dynamics of the within-day variation in prices in the VicPool. Nord Pool prices show the least complex within-day price dynamics of the three markets. Nord Pool prices are also by far the most forecastable of the three price series, as measured by the $R^{2}$ of the prediction regressions. E\&W market prices and VicPool prices are predictable with approximately the same average $R^{2}$ over all half-hour periods in the day. However, different from the VicPool, the highest priced load periods in the day in the E\&W market are uniformly the most forecastable by this same measure. Although the short length of the New Zealand price series required estimating a more parsimonious autoregressive process for these prices, the differences in the results across North Island and South Island prices were consistent with the results obtained for E\&W and VicPool prices versus Nord Pool prices.

I now characterize differences in the behavior of the spot prices within the day and week across the peak and off-peak months of the year. Figure $3.1 \mathrm{~A}$ plots the average behavior of normalized prices throughout the day for the E\&W market in winter (December, January, and February) and summer (June, July, and August). To compute the normalized price for any load period, I divide the actual price by the sample mean price of electricity in the E\&W market. Figure $3.1 B$ plots the behavior of normalized prices throughout the week in summer and winter. These plots illustrate an important feature of the behavior of prices in the E\&W market. During the winter months, all weekday prices become very high during load periods 35 to 37 . The average high price during weekdays (excluding Fridays) is more than 4.0 times the sample mean of the spot price in load periods 35 to 37. Wolak and Patrick (1996b) argue that this pattern of prices represents the exercise of market power by National Power and PowerGen, the two major generators in the E\&W market.

Figure 3.2 presents the day and week normalized price plots for Nord Pool. There appears to be little predictable variation in spot prices within the day and across days of the week in Nord Pool. The major movements in prices appear to be across the peak and off-peak seasons, with average summer prices significantly below average winter prices within the day and within the week. This reflects the view that water scarcity is a major determinant of prices in Nord Pool.

The average pattern of prices within the day and week in the VicPool shares features with both Nord Pool and the E\&W market (see fig. 3.3). For consistency with the other two figures, I have defined summer to be the months of June, July, and August and winter to be December, January, and February. For most half-hours, average prices in June, July, and August (summer) are higher than those in December, January, and February (winter). The differences in predictable price fluctuations within the day 

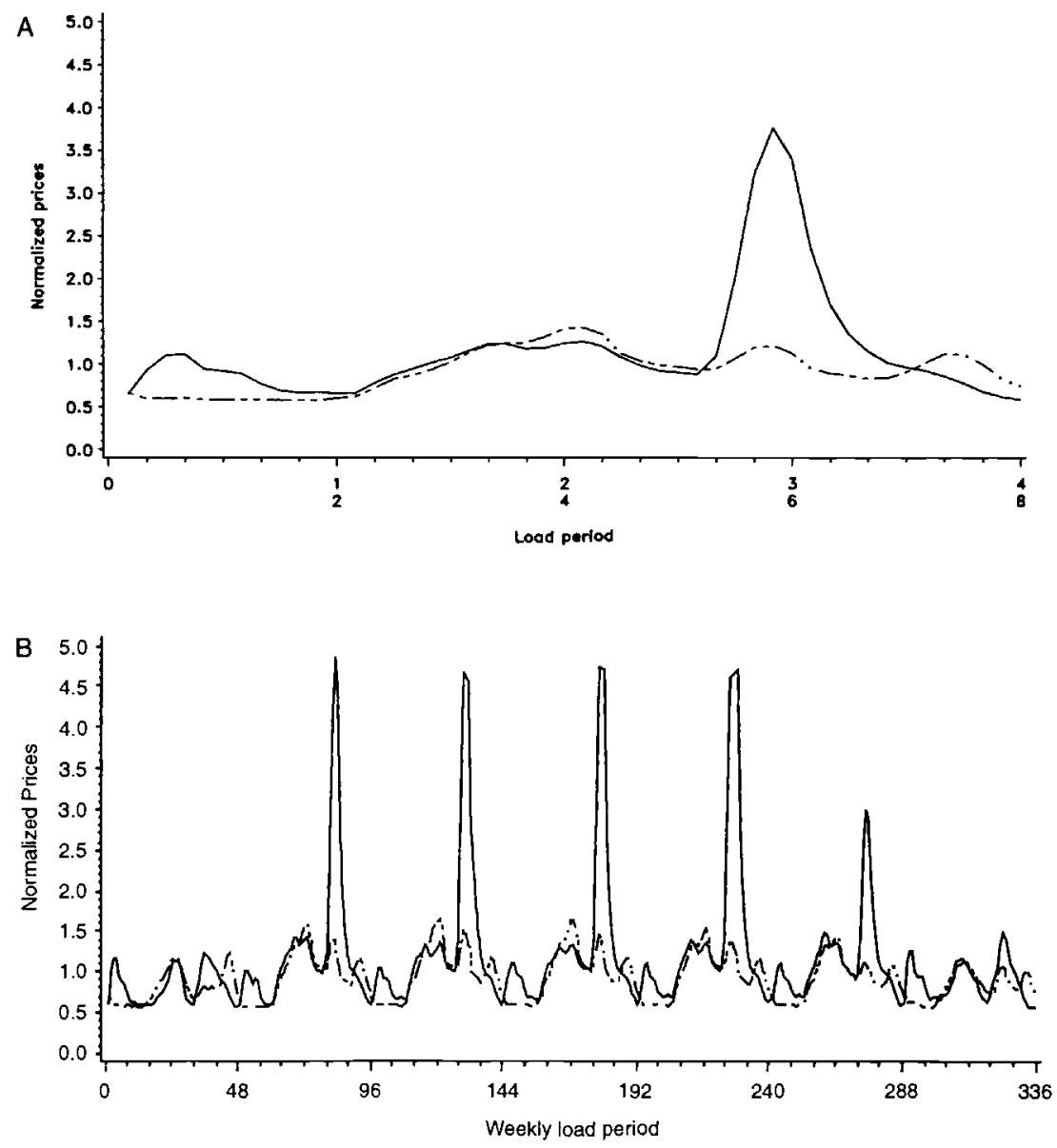

\section{- Winter prices}

Fig. 3.1 England and Wales: average prices throughout the day $(A)$ and the week $(B)$

and week across the peak and off-peak seasons is not nearly as pronounced in the VicPool as it is in the E\&W market. Both seasons exhibit more predictable variation within the day and week than do E\&W prices in the summer, but less than E\&W prices in the winter.

Because no data exist for New Zealand for the months of June, July, and August, figure 3.4 plots the average prices in North and South Islands throughout the day and week. The pattern of average prices within the day for both islands is very similar to the pattern of prices within the day 

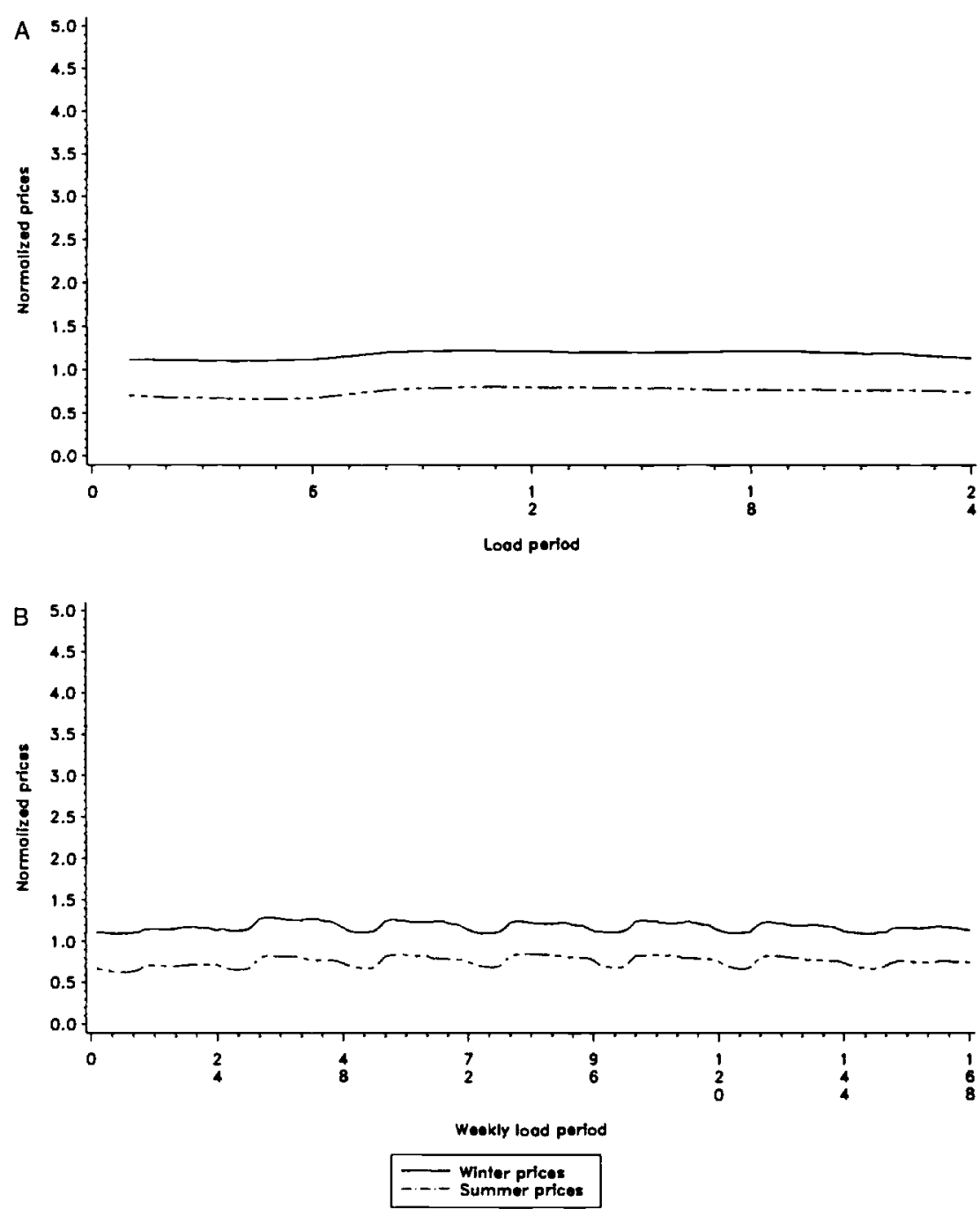

Fig. 3.2 Nord Pool: average prices throughout the day $(A)$ and the week $(B)$

for Nord Pool. A similar statement can be said about the behavior of both New Zealand prices within the week.

Figures 3.5, 3.6, and 3.7 plot the period-level standard deviations of normalized prices within the day for the E\&W market, Nord Pool, and the VicPool. Each point on this plot is the standard deviation of the normalized (by the overall sample mean price) price for that load period within the day for all days within that season. Figure 3.5 illustrates that although normalized prices in load periods 35 to 37 are known to be very 

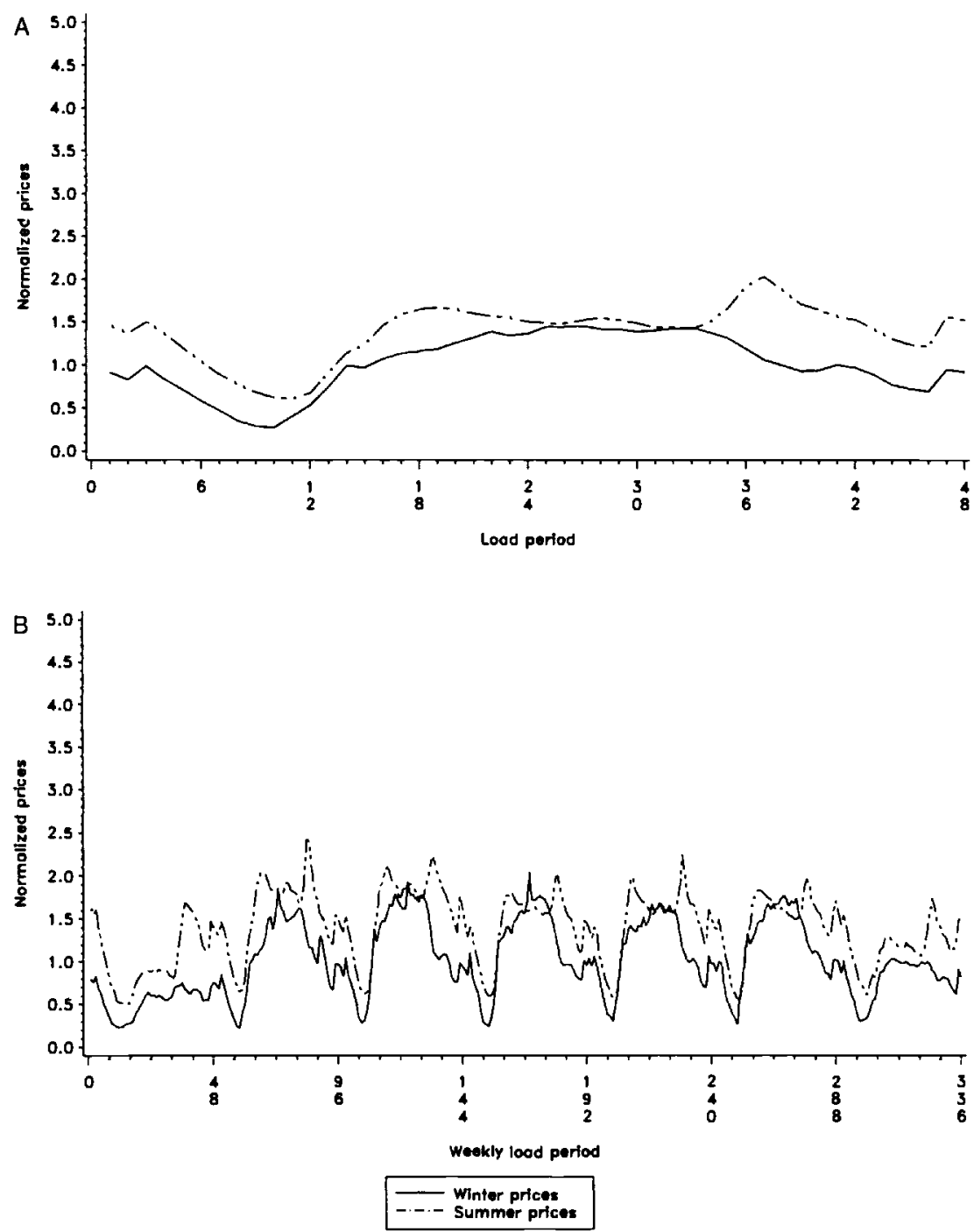

Fig. 3.3 VicPool: average prices throughout the day $(A)$ and the week $(B)$

high, there is considerable uncertainty about precisely how high they will be. Figure 3.6 tells a similar story for the case of mean prices within the day for Nord Pool. The uncertainty in normalized prices is uniform within the day in both summer and winter, but the uncertainty in normalized prices is uniformly higher in the summer than the winter.

Figure 3.7 illustrates that for the most part the degree of uncertainty in normalized prices is very similar across load periods in the VicPool. The 

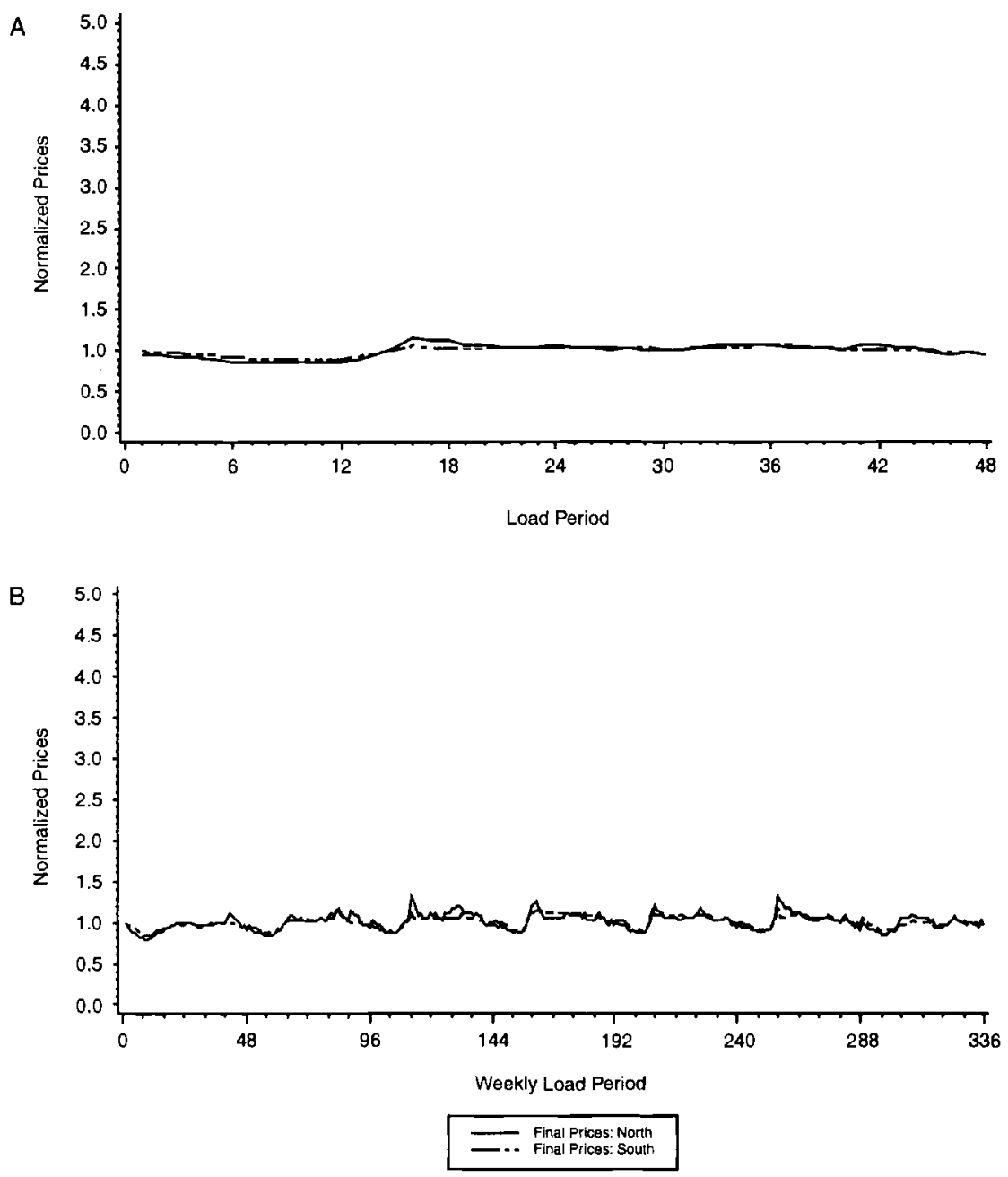

Fig. 3.4 New Zealand: average prices throughout the day $(A)$ and the week $(B)$

only exception is that during the high-priced periods in December, January, and February (the months of peak demand in Victoria), the uncertainty in normalized prices is highest during the highest priced periods of the day.

Figure 3.8 computes the period-level standard deviations in normalized prices for North Island and South Island prices in New Zealand. The pattern of uncertainty in these prices is very similar to the within-day uncertainty in prices in Nord Pool. The North Island standard deviations tend to be higher than the South Island standard deviations, particularly for the peak periods of the day, reflecting the use of fossil units during these time periods in North Island. 


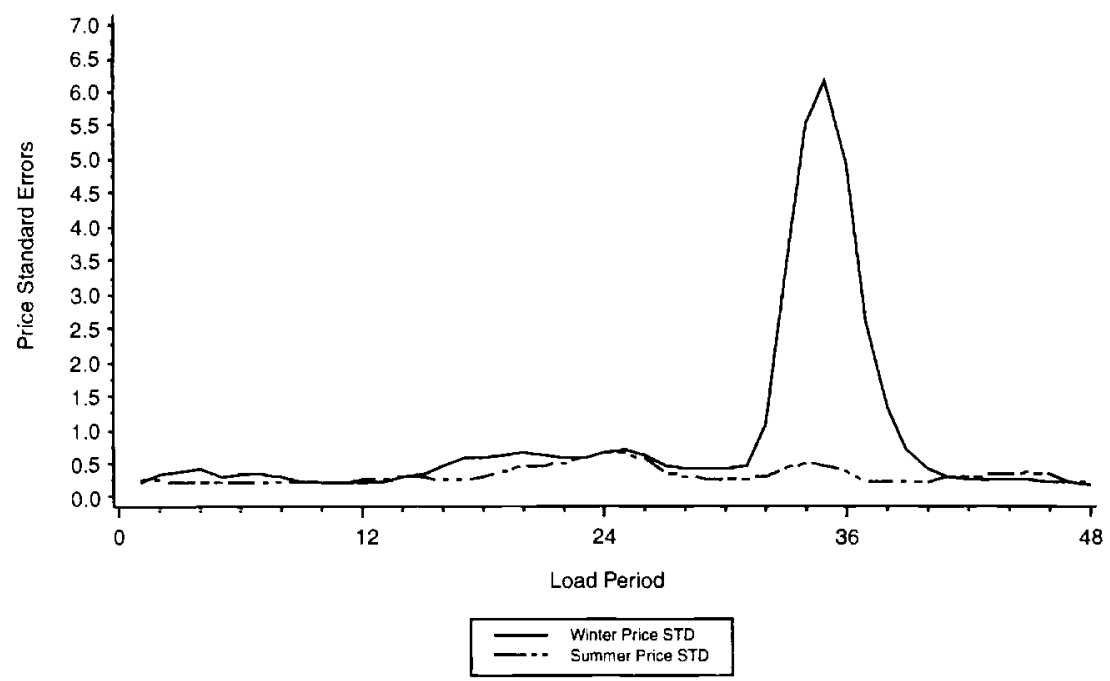

Fig. 3.5 England and Wales: standard deviation of prices throughout the day

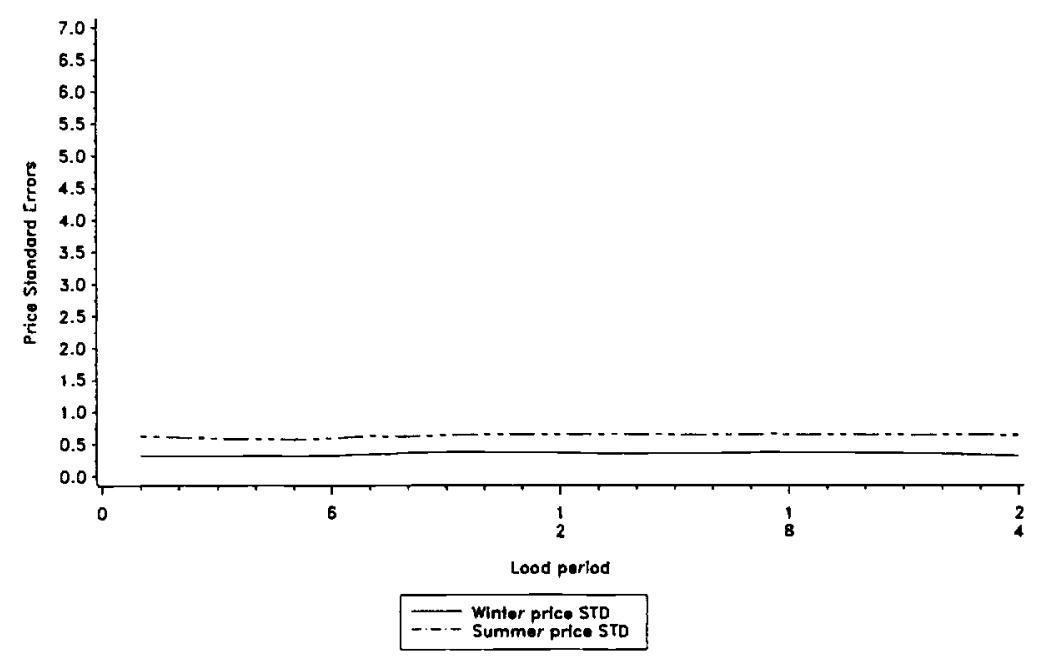

Fig. 3.6 Nord Pool: standard deviation of prices throughout the day

\subsection{Market Structure and Market Rules and the Exercise of Market Power}

A significantly more detailed analysis of each of these markets is required to draw conclusions about the exercise of market power in any of these markets. However, the strong influence that both market structure and market rules appear to exert on the behavior of prices in these markets 


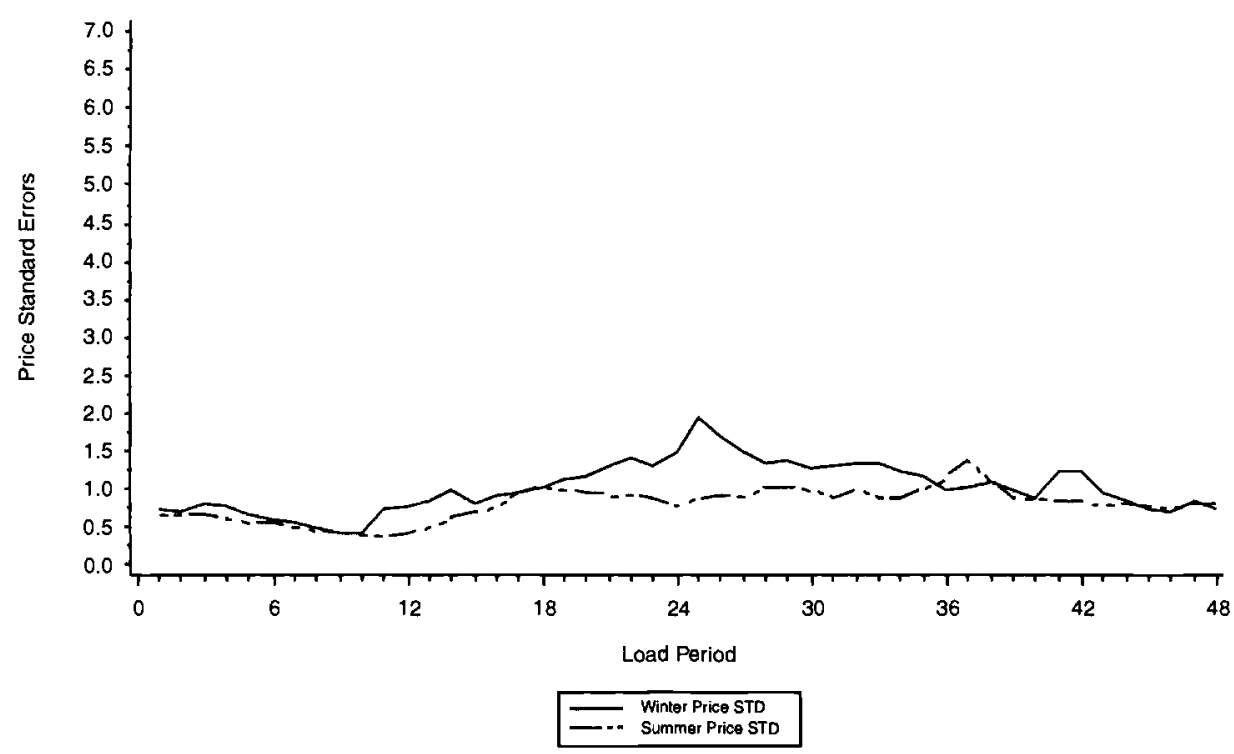

Fig. 3.7 VicPool: standard deviation of prices throughout the day

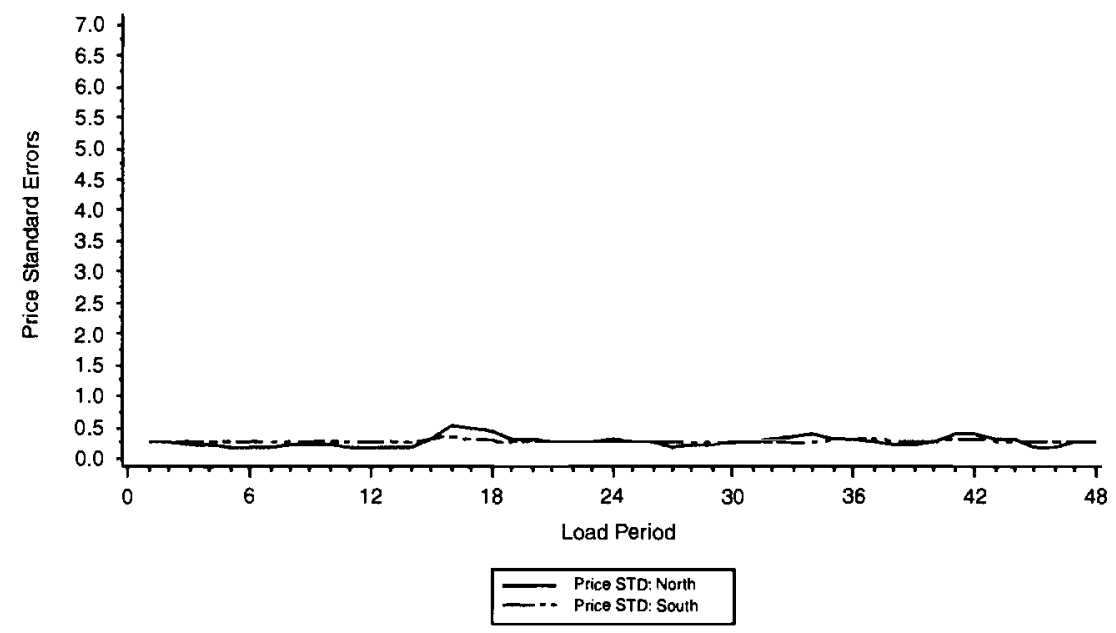

Fig. 3.8 New Zealand: standard deviation of prices throughout the day

suggests that such an across-country analysis should have significant promise to yield insights about how the interaction of market rules and market structure allows the exercise of market power.

The dramatically different pattern of average electricity prices within the day and within the week in the E\&W market relative to the other three markets does lend further support to the conclusion reached in Wolak and Patrick (1996a) that the two largest generators in the E\&W market- 
National Power and PowerGen-possess significant market power that they are able to exercise when certain conditions in the E\&W market make the residual demand they jointly face extremely large relative to the capacity of these two large generating companies.

The relatively flat pattern of average prices throughout the day in the VicPool and the very low U.S. dollar prices for electricity from this market in 1996 and 1997 seem indicative of a very competitive electricity market. The relatively high degree of volatility in prices throughout the day in the VicPool (compared to Nord Pool and the NZEM) seems to indicate that generators are sometimes successful at obtaining high prices, but just as often their efforts yield very low prices, so that on average, prices for electricity are very low. Consequently, the VicPool appears to be an example of a market where the efforts of generators to exercise market power are on average unsuccessful. The evidence on the behavior of prices appears consistent with the conclusion that it is a more competitive market than the E\&W market. Further research is necessary to determine whether this apparent difference in competitiveness is due to differences in market structure of the two markets or in market rules.

Nord Pool and the NZEM present a more difficult puzzle because both markets are dominated by large state-owned enterprises. We would not expect these firms to exercise market power with the same vigor that privately owned firms do. Nevertheless, both of these electricity supply industries produce the vast majority of their power from very inexpensive hydroelectric resources, so the higher U.S. dollar prices in these two markets relative to Victoria do raise suspicions about the exercise of market power by the large state-owned firms. As discussed earlier, in the fall of 1992, Statkraft publicly announced a policy to keep spot prices above 100 NOK/ MWH, although subsequently prices have fallen below this level for long periods of time. The evidence from the behavior of prices in both Nord Pool and the NZEM relative to prices in Victoria and the E\&W market seems to indicate that the large state-owned generators in Nord Pool and the NZEM are price leaders with the remaining firms serving as a competitive fringe. Further analysis of both of these markets is necessary to reach a more definitive conclusion about whether these outcomes represent market power.

\section{References}

Armstrong, Mark, Simon Cowan, and John Vickers. 1994. Regulatory reform: Economic analysis and British experience. Cambridge, Mass.: MIT Press.

Baker, A. B. 1992. The methodology and process of forecasting nominal demand. GSMNC/ABB/DF 5.1.2.9. Coventry, England: National Grid Company, Grid System Management, National Control. 
Box, G. E. P., and David A. Pierce. 1970. Distribution of residual autocorrelations in autoregressive-integrated moving average time series models. Journal of the American Statistical Association 65:1509-26.

Electricity Association. 1997. Electricity industry review. London: Electricity Association Services Limited, Business Information Center. Document available from Electricity Association, http://www.electricity.org.uk.

Electricity Pool of England and Wales. 1997. Schedule 9: The pool rules. Pooling and Settlement Agreement for the Electricity Industry in England and Wales, issue no. 45, version 6.20, 1 February. Binder available from Electricity Pool of England and Wales, 338 Enston Road, 10th Floor, Regent's Place, London NWI 3BP.

. n.d. Introduction to pool rules, issue no. 2. Document available from Electricity Pool of England and Wales, 338 Enston Road, 10th Floor, Regent's Place, London NW1 3BP.

Green, Richard J. 1999. The electricity contract market in England and Wales. Journal of Industrial Economics 47 (1): 107-24.

Helm, Dieter, and Andrew Powell. 1992. Pool prices, contracts and regulation in the British electricity supply industry. Fiscal Studies 13 (1): 89-105.

Hosking, J. R. M. 1980. The multivariate portmanteau statistic. Journal of the American Statistical Association 75:602-8.

Joskow, Paul. 1987. Productivity growth and technical change in the generation of electricity. Energy Journal 8 (1): 17-38.

Lee, Byung-Joo. 1995. Separability test for the electricity supply industry. Journal of Applied Econometrics 10:49-60.

National Grid Company. 1995. 1995 Seven year statement. Coventry, England: National Grid Company.

Patrick, Robert H., and Frank A. Wolak. 1997. Estimating customer-level demand for electricity under real time pricing. March. Document available from http:// www.stanford.edu/ - wolak.

Reed, E. Grant, Glenn R. Drayton-Bright, and Brendan J. Ring. 1998. An integrated energy and reserve market for New Zealand. Energy Modelling Research Group Working Paper no. EMRG-WP-98-01. Christchurch, New Zealand: University of Canterbury, Department of Management.

Wolak, Frank A., and Robert H. Patrick. 1996a. The impact of market rules and market structure on the price determination process in the England and Wales electricity market. June. Document available from http://www.stanford.edu/ -wolak.

1996b. Industry structure and regulation in the England and Wales electricity market. In Pricing and regulatory innovations under increasing competition, ed. M. A. Crew, 65-90. Amsterdam: Kluwer.

\section{Comment Takatoshi Ito}

This is a well-structured, detailed paper on comparing structural changes in the electricity industries in selected countries and regions (Norway and Sweden, New Zealand, England and Wales, and Victoria). The following

Takatoshi Ito is professor in the Institute of Economic Research at Hitotsubashi University, Tokyo, and a research associate of the National Bureau of Economic Research. 
three aspects stand out as interesting points in this paper. First, the electricity industry was considered a typical example of a natural monopoly only fifteen years ago. This is no longer true. However, perfect competition is obviously not the case. Hence the problem is how to set a "market rule" to produce efficient and fair outcomes. Second, the industry is composed of two different subindustries, power generation and power distribution (transmission). It seems to be the trend that these two subindustries can be treated differently. Power generation can be privatized more easily. Third, trade aspects of the electricity industry depend on the location of the country. Obviously, Scandinavian countries can trade electricity more easily than Japan can with its neighbors. Let me elaborate on these points, especially from the viewpoint of lessons for Asian countries.

First, it is good to see players respond to incentives, as detailed in the paper. Also, prices for electricity behave as theory predicts, according to market structure and market rules. It is shown that some larger companies reduce scale instead of expanding market share. This underscores the importance of setting the right market rule. But what is the optimal market rule? The paper indicates that the market rule depends on the type of power generation-oil, hydroelectric, or nuclear. The market rule should be designed to reflect such differences, so a country or even a region (an island) of a country has to design its own market rule.

Second, power generation and power distribution may be two different industries as far as market structure goes. Even Japan, a country often regarded as lagging in deregulation, has moved to deregulate power generation. Regular companies can sell power to the public power companies (regional monopolies). Power distribution is similar to telephone service, railroad service, or any other distribution or transportation sector. There is tension between universal service and efficient allocation of resources. Power generation can be much more competitive. Many manufacturing companies potentially have capacity in power generation that can be sold back to the power company that distributes to retail customers. It is difficult to decide how to compensate quality (penalties for blackout? Subsidies to current stability and universal service?).

Third, in thinking of trade aspects, the national boundary may not be a natural boundary of the industry. The examples in this paper, an arrangement between England and Wales and one between Norway and Sweden, show the extent and structure of a pool arrangement. A similar examination can be made, for example, of an arrangement between the regional monopolies in Japan. Another interesting aspect of the Japanese situation is that power plants were required to use domestic high-cost coal. If they were allowed to import coal, electricity prices may have been lower.

Two important aspects that are beyond the scope of this paper deserve future research. Power generation types differ in many countries. France produces more than three-quarters of its electricity from nuclear power 
plants, while Germany, Japan, and the United Kingdom produce about one-quarter of their power from nuclear plants. More than 60 percent of Canadian power is produced from hydroelectric power plants. These ratios reflect both the natural endowments of countries and policy decisions. An important question is whether decisions concerning types of power generation should anticipate the market structure, which is governed by the (mix of) types of power generation. Until now, decisions about electric power have not considered the competition aspects of the industry.

Alternative sources of electricity have been sought after. Locations for hydroelectric power plants have been exhausted in many advanced countries, nuclear energy carries nuclear danger, and oil-burning plants produce air pollution, although more advanced plants have cleaner technology. Whether R\&D in alternative sources should be subsidized, and if so whether the funds should be cross-subsidized from existing companies (customers), is an interesting question.

Last, long after the conference in 1998, there was a prolonged blackout in New Zealand, one of the countries studied in this paper. A discussion of whether the power failure had anything to do with the market rule in that country would have been interesting.

\section{Comment Francis T. Lui}

Frank Wolak has written a very readable paper from which I have learned a great deal. The paper consists of two parts. The first is a detailed description of the market structure, market rules, and regulatory oversight of electricity markets in four different economies. The second is an empirical investigation of various aspects of the movement of electricity prices in the four economies. I will comment on each part separately.

Knowing little about the electricity market and coming from a place where the regulatory system is relatively simple, I was surprised to learn of the elaborate institutional arrangements and regulatory schemes in the four economies. Suppose some undesirable consequences occur because of the imposition of a regulatory rule. Then there seem to be two approaches to dealing with them. One is to get rid of the regulation or barriers to entry. This allows the free market to come in again as an alternative. The other is to design and introduce a more complicated set of new regulations. These possibly incentive-compatible regulations may mitigate the undesirable effects found earlier. The sample of countries under study seems to have chosen the second way.

Francis T. Lui is director of the Center for Economic Development at the Hong Kong University of Science and Technology. 
Is this a good approach? The answer is not clear to me. In Hong Kong, China Light, the power company that supplies 80 percent of the electricity, is heavily regulated. Its profits cannot exceed a certain percentage of its assets. It has therefore decided to expand capacity rapidly, with the result that the maximum capacity is far bigger than peak load demand. On the other hand, the unregulated and sole provider of gas, Town Gas, enjoys a total factor productivity growth of 2 percent per annum. Wolak has collected a lot of data about the electricity market. It would be interesting to test from the data whether a complicated regulatory system can beat the free market.

Another interesting issue is the political economy of how different places have adopted their own systems. Have they emerged because of political bargaining? Are they the intellectual products of some academics that are influential enough to implement their ideas? If political bargaining is the main reason, there is no guarantee that the resulting regulatory structure is optimal. It would be nice if the author could tell us more about the political economy background.

The empirical part of the paper uses a number of techniques to investigate various properties of electricity prices-for example, forecastability of prices, their variability, and whether their changes can be explained by just a few factors. Most of the results and interpretations seem to be reasonable. However, are the tests used powerful enough to answer the basic question, namely, how does market power depend on market structure and market rules? In a sense, we have learned that (1) the price movements are different and (2) there are many technological and institutional differences across the countries. However, can we be sure that the price behavior is due mainly to the market structure and market rules? There are only four places and four sets of observations. Is the basic question answerable?

One way to make the answer more convincing is to construct data sets from many more countries. Then more information can be used for testing hypotheses. Another way is to identify refutable hypotheses from the first part of the paper and implement a number of tests in the second part. The linkage between the two parts is not too clear in some cases. Sometimes, the differences in price movements do not seem to have much to do with market rules and market structure. For example, the prices in Nord Pool are more predictable, but there is apparently just one dominating explanatory variable, namely, whether there is enough water supply for hydroelectricity. There seems to be a need to articulate the discussion so that the linkage between the two parts of the paper is explicit and the hypotheses of the first part are tested.

All in all, I like the paper. One can learn a lot of details about the individual countries by reading it. 